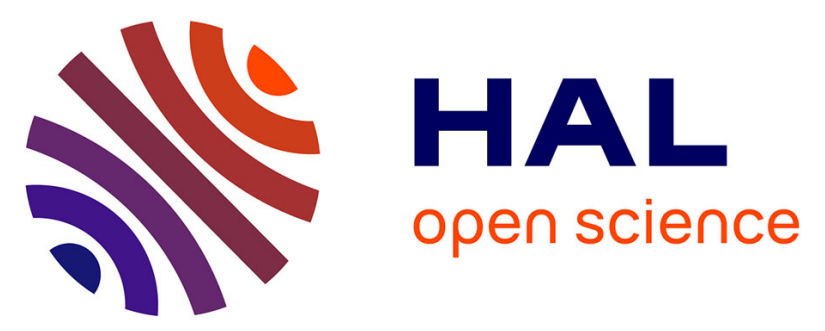

\title{
1,2-, 1,3- and 1,4-Phenylenediacetate Complexes of Uranyl Ion with Additional Metal Cations and/or Ancillary N-Donor Ligands: Confronting Ligand Geometrical Proclivities
}

Pierre Thuéry, Youssef Atoini, Jack Harrowfield

\section{To cite this version:}

Pierre Thuéry, Youssef Atoini, Jack Harrowfield. 1,2-, 1,3- and 1,4-Phenylenediacetate Complexes of Uranyl Ion with Additional Metal Cations and/or Ancillary N-Donor Ligands: Confronting Ligand Geometrical Proclivities. Crystal Growth \& Design, In press, 19, pp.6611-6626. 10.1021/acs.cgd.9b01032 . cea-02292579

HAL Id: cea-02292579

https://hal-cea.archives-ouvertes.fr/cea-02292579

Submitted on 20 Sep 2019

HAL is a multi-disciplinary open access archive for the deposit and dissemination of scientific research documents, whether they are published or not. The documents may come from teaching and research institutions in France or abroad, or from public or private research centers.
L'archive ouverte pluridisciplinaire HAL, est destinée au dépôt et à la diffusion de documents scientifiques de niveau recherche, publiés ou non, émanant des établissements d'enseignement et de recherche français ou étrangers, des laboratoires publics ou privés. 


\title{
1,2-, 1,3- and 1,4-Phenylenediacetate Complexes of Uranyl Ion with Additional Metal Cations and/or Ancillary $N$-Donor Ligands: Confronting Ligand Geometrical Proclivities
}

\author{
Pierre Thuéry, ${ }^{*}, \dagger$ Youssef Atoini ${ }^{\ddagger}$ and Jack Harrowfield ${ }^{*}+$ \\ †NIMBE, CEA, CNRS, Université Paris-Saclay, CEA Saclay, 91191 Gif-sur-Yvette, France \\ ISIS, Université de Strasbourg, 8 allée Gaspard Monge, 67083 Strasbourg, France
}

\begin{abstract}
Fourteen uranyl ion complexes have been obtained from reaction of 1,2- 1,3-, or 1,4phenylenediacetic acids $\left(1,2-1,3-\right.$, or 1,4- $\left.\mathrm{H}_{2} \mathrm{PDA}\right)$ with uranyl nitrate under solvo-hydrothermal conditions and in the presence of diverse additional metal ions and/or $N$-donor chelating or macrocyclic species. The complexes

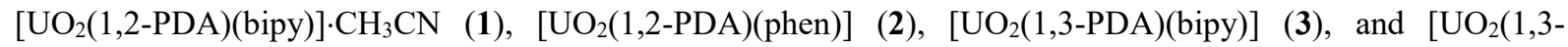
PDA)(phen)] (4), where bipy $=2,2^{\prime}$-bipyridine and phen $=1,10$-phenanthroline, crystallize as simple monoperiodic (1D) coordination polymers with slightly variable geometry and mode of association through weak interactions. Complex 5, $\left[\mathrm{H}_{2}-2.2 .2\right]\left[\left(\mathrm{UO}_{2}\right)_{2}(1,2-\mathrm{PDA})_{3}\right] \cdot \mathrm{CH}_{3} \mathrm{CN}$, containing diprotonated [2.2.2]cryptand, crystallizes as a ladderlike 1D polymer, while $\left[\mathrm{NH}_{4}\right]_{6}\left[\mathrm{Ni}_{2}\left(\mathrm{H}_{2} \mathrm{O}\right)_{6}\right]_{2}\left[\left(\mathrm{UO}_{2}\right)_{4}(1,2-\mathrm{PDA})_{6}\right]_{2}\left[\left(\mathrm{UO}_{2}\right)_{4}(1,2-\mathrm{PDA})_{5}\left(\mathrm{H}_{2} \mathrm{O}\right)_{4}\right](6)$ contains both a heavily corrugated 1D subunit and a discrete, tetranuclear anionic complex. The three complexes $\left.[\mathrm{Cu} \text { (bipy) })_{2}\left(\mathrm{NO}_{3}\right)\right]\left[\mathrm{UO}_{2}(1,2-\mathrm{PDA})\left(\mathrm{NO}_{3}\right)\right]$ (7), $\left[\mathrm{Ag}(\text { bipy })_{2}\right]\left[\mathrm{UO}_{2}(1,2-\mathrm{PDA})\left(\mathrm{NO}_{3}\right)\right](\mathbf{8})$, and $\left[\mathrm{Ag}(\text { bipy })_{2}\right]\left[\mathrm{UO}_{2}(1,4-\right.$ $\mathrm{PDA})\left(\mathrm{NO}_{3}\right)$ ] (9) display 1D arrangements close to those in complexes 1-4 due to the presence of terminal nitrate ligands. The heterometallic complex $\left[\mathrm{UO}_{2} \mathrm{~Pb}(1,3-\mathrm{PDA})_{2}\right.$ (phen) $]$ (10) crystallizes as a diperiodic (2D) network built from $1 \mathrm{D}$ ribbons arranged in roof-tile fashion and connected to one another by $\mathrm{Pb}-\mathrm{O}(\mathrm{oxo})$ links. $\left[\left(\mathrm{UO}_{2}\right)_{2} \mathrm{~Pb}_{2}(1,4-\right.$ $\left.\mathrm{PDA})_{3}(\mathrm{HCOO})_{2}(\text { phen })_{2}\right]$ (11) displays 1D triple-stranded $\left(\mathrm{UO}_{2}\right)_{2}(1,4-\mathrm{PDA})_{3}{ }^{2-}$ subunits assembled into a corrugated $2 \mathrm{D}$ polymer by double rows of $\mathrm{Pb}(\mathrm{HCOO})(\text { phen })^{+}$bridges. $\left[\mathrm{Zn}(\text { bipy })_{3}\right]\left[\left(\mathrm{UO}_{2}\right)_{2}(1,2-\mathrm{PDA})(1,4-\right.$ $\left.\mathrm{PDA})_{2}\right] \cdot \mathrm{H}_{2} \mathrm{O}$ (12) contains two phenylenediacetate isomers and displays zigzag chains linked to one another by dinuclear rings to give a $2 \mathrm{D}$ assembly containing large, elongated decanuclear rings. The two complexes $[\mathrm{Cu}(R, S-$ $\mathrm{Me}_{6}$ cyclam $\left.)\right]\left[\mathrm{UO}_{2}(1,3-\mathrm{PDA})\left(\mathrm{NO}_{3}\right)\right]_{2}(\mathbf{1 3})$ and $[\mathrm{Ni}(\mathrm{cyclam})]\left[\left(\mathrm{UO}_{2}\right)_{2}(1,3-\mathrm{PDA})_{3}\right](\mathbf{1 4})$, where cyclam $=1,4,8,11$ tetraazacyclotetradecane and $R, S-\mathrm{Me}_{6}$ cyclam $=7(R), 14(S)-5,5,7,12,12,14$-hexamethylcyclam, are a $1 \mathrm{D}$ polymer analogous to 7-9 and a 2D species containing triple-stranded subunits similar to those in 11, respectively. These and previous results show that the phenylenediacetate ligands have a strong propensity to give 1D polymers with uranyl ion, which can only be partially overcome through the incorporation of additional metal cations, either bound to $N$-donors to form bulky, structure-directing counterions, or part of heterometallic polymers.
\end{abstract}




\section{INTRODUCTION}

Polycarboxylates have been widely investigated as ligands for uranyl ion and the variety of the structural chemistry revealed is quite remarkable. ${ }^{1-5}$ Within this variety, however, uranium(VI), as uranyl ion derivatives, is most often in coordination environments idealized as either pentagonal- or hexagonal-bipyramidal. These are coordination modes rarely found outside the actinide elements, and they give rise to many unique features in the structural chemistry of uranyl complexes. One consequence, a drawback in regard to the creation of triperiodic networks, is the quasi-planar geometry of many polymeric assemblies based on this cation, ${ }^{6}$ and it is thus of interest to define ways in which the periodicity of such assemblies may be modulated. Uranyl ion has a great affinity for carboxylate ligands, ${ }^{3}$ which provide a wide scope for exploration since, apart from the sheer diversity of available carboxylate derivatives, the carboxylate entity is a versatile donor and is found in uranyl ion complexes in $\kappa^{1} O, \kappa^{2} O, O^{\prime}, \mu_{2}-$ $\kappa^{1} O: \kappa^{1} O^{\prime}, \quad \mu_{2}-\kappa^{2} O, O^{\prime}: \kappa^{1} O^{\prime}$ and $\mu_{3}-\kappa^{1} O: \kappa^{2} O, O^{\prime}: \kappa^{1} O^{\prime}$ coordination modes, although $\kappa^{1} O$ coordination is relatively rare and largely associated with but the simplest carboxylate, formate. ${ }^{7-9}$ The next simplest carboxylate, acetate, has long been known to provide tris(acetato) species in which the uranium cation is in hexagonal bipyramidal coordination and the acetate is chelated to uranium but also bridges to sodium $\left(\mu_{2}-\kappa^{2} O, O^{\prime}: \kappa^{1} O^{\prime}\right.$ mode $),{ }^{10-12}$ thus suggesting a path to increase periodicity through the introduction of additional cations. Although trischelation is also frequent with polycarboxylates, the wide range of coordination modes and secondary interactions depending on the ligand geometry, as well as sensitivity to structuredirecting effects, leave much room for the formation of variously shaped molecular assemblies or polymeric architectures. During our investigation of uranyl complexes with flexible dicarboxylic acids in the presence of a variety of counterions, ${ }^{13-15}$ we have recently shown that the three positional isomers of phenylenediacetic acid, when associated with counterions of the form $\left[\mathrm{M}(\mathrm{L})_{n}\right]^{q^{+}}$, in which $\mathrm{M}=$ transition metal cation, $\mathrm{L}=2,2^{\prime}$-bipyridine (bipy) or 1,10 - 
phenanthroline (phen), $n=2$ or 3 , and $q=1$ or 2 , gave uranyl ion complexes crystallizing as mono- or diperiodic (denoted 1D or 2D for convenience) assemblies, the 1D polymers displaying in some cases a tubelike geometry. ${ }^{16}$ In order to investigate more fully the structuredirecting role of counterions or coligands with this family of closely related phenylenedicarboxylates, and the possible differences related to the isomeric form chosen, we have now synthesized 14 complexes which have been characterized by their crystal structure and, in most cases, their emission spectrum in the solid state. These complexes incorporate either only the $N$-donors bipy and phen as coligands on uranium, or involve counterions such as diprotonated [2.2.2]cryptand $(4,7,13,16,21,24-h$ exaoxa-1,10diazabicyclo[8.8.8]hexacosane) or different metal cations $\left(\mathrm{Ni}^{2+}, \mathrm{Cu}^{2+}, \mathrm{Zn}^{2+}, \mathrm{Ag}^{+}\right.$or $\left.\mathrm{Pb}^{2+}\right)$ associated with $N$-chelators (bipy, phen, cyclam $=1,4,8,11$-tetraazacyclotetradecane, $R, S$ $\mathrm{Me}_{6}$ cyclam $=7(R), 14(S)-5,5,7,12,12,14$-hexamethylcyclam). The results obtained show that although these ligands have a very strong tendency to form 1D coordination polymers, a degree of modulation is still possible, leading to several 2D networks.

\section{EXPERIMENTAL SECTION}

Syntheses. Caution! Uranium is a radioactive and chemically toxic element, and uranium-containing samples must be handled with suitable care and protection.

$\mathrm{UO}_{2}\left(\mathrm{NO}_{3}\right)_{2} \cdot 6 \mathrm{H}_{2} \mathrm{O}$ (depleted uranium, R. P. Normapur, 99\%), $\mathrm{Ni}\left(\mathrm{NO}_{3}\right)_{2} \cdot 6 \mathrm{H}_{2} \mathrm{O}, \mathrm{AgNO}_{3}$ and $\mathrm{Pb}\left(\mathrm{NO}_{3}\right)_{2}$ were purchased from Prolabo. $\mathrm{Cu}\left(\mathrm{NO}_{3}\right)_{2} \cdot 2.5 \mathrm{H}_{2} \mathrm{O}, \mathrm{Zn}\left(\mathrm{NO}_{3}\right)_{2} \cdot 6 \mathrm{H}_{2} \mathrm{O}, 1,2-, 1,3-$ and 1,4-phenylenediacetic acids, 1,10-phenanthroline, and [2.2.2]cryptand (4,7,13,16,21,24hexaoxa-1,10-diazabicyclo[8.8.8]hexacosane) were from Aldrich, while 2,2'-bipyridine was from Fluka. [Ni(cyclam $\left.)\left(\mathrm{NO}_{3}\right)_{2}\right]$ and $\mathrm{N}(R, S, R, S)-\left[\mathrm{Cu}\left(R, S-\mathrm{Me}_{6}\right.\right.$ cyclam $\left.)\left(\mathrm{NO}_{3}\right)_{2}\right]$ were synthesized as previously reported. ${ }^{17,18}$ Elemental analyses were performed by MEDAC Ltd. at Chobham, UK. For all syntheses, the mixtures in demineralized water/organic solvent were 
placed in $10 \mathrm{~mL}$ tightly closed glass vessels and heated at $140{ }^{\circ} \mathrm{C}$ under autogenous pressure. A summary of the reactants used in each case is given in Table 1.

Table 1. Reactants Used in the Syntheses

\begin{tabular}{cllll}
\hline & carboxylic acid & $\begin{array}{c}\text { organic } \\
\text { cosolvent }\end{array}$ & $\begin{array}{c}\text { additional } \\
\text { metal cation }\end{array}$ & N-donor ligand \\
\hline $\mathbf{1}$ & $1,2-\mathrm{H}_{2} \mathrm{PDA}$ & acetonitrile & $\left(\mathrm{Ni}^{2+}\right)$ & bipy \\
$\mathbf{2}$ & $1,2-\mathrm{H}_{2} \mathrm{PDA}$ & acetonitrile & $\left(\mathrm{Pb}^{2+}\right)$ & phen \\
$\mathbf{3}$ & $1,3-\mathrm{H}_{2} \mathrm{PDA}$ & acetonitrile & & bipy \\
$\mathbf{4}$ & $1,3-\mathrm{H}_{2} \mathrm{PDA}$ & acetonitrile & & phen \\
$\mathbf{5}$ & $1,2-\mathrm{H}_{2} \mathrm{PDA}$ & acetonitrile & $\left(\mathrm{Li}^{+}\right)$ & {$[2.2 .2] \mathrm{cryptand}$} \\
$\mathbf{6}$ & $1,2-\mathrm{H}_{2} \mathrm{PDA}$ & acetonitrile & $\mathrm{Ni}^{2+}$ & \\
$\mathbf{7}$ & $1,2-\mathrm{H}_{2} \mathrm{PDA}$ & acetonitrile & $\mathrm{Cu}^{2+}$ & bipy \\
$\mathbf{8}$ & $1,2-\mathrm{H}_{2} \mathrm{PDA}$ & acetonitrile & $\mathrm{Ag}^{+}$ & bipy \\
$\mathbf{9}$ & $1,4-\mathrm{H}_{2} \mathrm{PDA}$ & acetonitrile & $\mathrm{Ag}^{+}$ & bipy \\
$\mathbf{1 0}$ & $1,3-\mathrm{H}_{2} \mathrm{PDA}$ & DMF & $\mathrm{Pb}^{2+}$ & phen \\
$\mathbf{1 1}$ & $1,4-\mathrm{H}_{2} \mathrm{PDA}$ & DMF & $\mathrm{Pb}^{2}$ & phen \\
$\mathbf{1 2}$ & $1,2-1,4-\mathrm{H}_{2} \mathrm{PDA}$ & DMF & $\mathrm{Zn}^{2+}$ & bipy \\
$\mathbf{1 3}$ & $1,3-\mathrm{H}_{2} \mathrm{PDA}$ & acetonitrile & $\mathrm{Cu}^{2+}$ & $R, S$-Me 6 cyclam \\
$\mathbf{1 4}$ & $1,3-\mathrm{H}_{2} \mathrm{PDA}$ & acetonitrile & $\mathrm{Ni}^{2+}$ & cyclam \\
\hline
\end{tabular}

${ }^{a}$ Metal cations in parentheses are absent from the final compounds.

$\left[\cup \mathrm{O}_{2}(1,2-P D A)(\right.$ bipy) $] \cdot \mathrm{CH}_{3} \mathrm{CN}$ (1). 1,2-Phenylenediacetic acid (20 mg, $\left.0.10 \mathrm{mmol}\right)$, $\mathrm{UO}_{2}\left(\mathrm{NO}_{3}\right)_{2} \cdot 6 \mathrm{H}_{2} \mathrm{O}(35 \mathrm{mg}, 0.07 \mathrm{mmol}), \mathrm{Ni}\left(\mathrm{NO}_{3}\right)_{2} \cdot 6 \mathrm{H}_{2} \mathrm{O}(15 \mathrm{mg}, 0.05 \mathrm{mmol})$, and 2,2'bipyridine $(32 \mathrm{mg}, 0.20 \mathrm{mmol})$ were dissolved in water $(1.7 \mathrm{~mL})$ and acetonitrile $(0.2 \mathrm{~mL})$. Yellow crystals of complex 1 were obtained within two weeks (4 mg, 9\% yield based on U). Anal. Calcd for $\mathrm{C}_{22} \mathrm{H}_{19} \mathrm{~N}_{3} \mathrm{O}_{6} \mathrm{U}: \mathrm{C}, 40.07 ; \mathrm{H}, 2.90 ; \mathrm{N}, 6.37$. Found: C, 39.90; H, 2.81; N, 6.32\%. $\left[\cup \mathrm{O}_{2}(1,2-P D A)(\right.$ phen)] (2). 1,2-Phenylenediacetic acid $(20 \mathrm{mg}, 0.10 \mathrm{mmol})$, $\mathrm{UO}_{2}\left(\mathrm{NO}_{3}\right)_{2} \cdot 6 \mathrm{H}_{2} \mathrm{O}(35 \mathrm{mg}, 0.07 \mathrm{mmol}), \mathrm{Pb}\left(\mathrm{NO}_{3}\right)_{2}(33 \mathrm{mg}, 0.10 \mathrm{mmol})$, and 1,10-phenanthroline 
$(18 \mathrm{mg}, 0.10 \mathrm{mmol})$ were dissolved in water $(0.9 \mathrm{~mL})$ and acetonitrile $(0.2 \mathrm{~mL})$. Yellow crystals of complex 2 were obtained in low yield within three days.

$\left[\cup \mathrm{O}_{2}(1,3-P D A)(\right.$ bipy) $]$ (3). 1,3-Phenylenediacetic acid (20 $\left.\mathrm{mg}, \quad 0.10 \mathrm{mmol}\right)$, $\mathrm{UO}_{2}\left(\mathrm{NO}_{3}\right)_{2} \cdot 6 \mathrm{H}_{2} \mathrm{O}(50 \mathrm{mg}, 0.10 \mathrm{mmol})$, and 2,2'-bipyridine (32 $\left.\mathrm{mg}, 0.20 \mathrm{mmol}\right)$ were dissolved in water $(1.2 \mathrm{~mL})$ and acetonitrile $(0.2 \mathrm{~mL})$. Yellow crystals of complex 3 were obtained in low yield within one week.

$\left[\cup \mathrm{O}_{2}(1,3-P D A)(\right.$ phen)] (4). 1,3-Phenylenediacetic acid $(20 \mathrm{mg}, \quad 0.10 \mathrm{mmol})$, $\mathrm{UO}_{2}\left(\mathrm{NO}_{3}\right)_{2} \cdot 6 \mathrm{H}_{2} \mathrm{O}(50 \mathrm{mg}, 0.10 \mathrm{mmol})$, and 1,10-phenanthroline $(18 \mathrm{mg}, 0.10 \mathrm{mmol})$ were dissolved in water $(0.9 \mathrm{~mL})$ and acetonitrile $(0.2 \mathrm{~mL})$. Yellow crystals of complex 4 were obtained within one week (22 mg, 34\% yield). Anal. Calcd for $\mathrm{C}_{22} \mathrm{H}_{16} \mathrm{~N}_{2} \mathrm{O}_{6} \mathrm{U}$ : C, 41.13; H, 2.51; N, 4.36. Found: C, 40.77; H, 2.55; N, 4.41\%.

$\left[\mathrm{H}_{2}-2.2 \cdot 2\right]\left[\left(\mathrm{UO}_{2}\right)_{2}(1,2-P D A)_{3}\right] \cdot \mathrm{CH}_{3} \mathrm{CN}$ (5). 1,2-Phenylenediacetic acid (20 $\mathrm{mg}, 0.10$ mmol), $\mathrm{UO}_{2}\left(\mathrm{NO}_{3}\right)_{2} \cdot 6 \mathrm{H}_{2} \mathrm{O}(35 \mathrm{mg}, 0.07 \mathrm{mmol}), \mathrm{LiNO}_{3}(14 \mathrm{mg}, 0.20 \mathrm{mmol})$, and [2.2.2]cryptand (38 mg, $0.10 \mathrm{mmol})$ were dissolved in water $(1.2 \mathrm{~mL})$ and acetonitrile $(0.3 \mathrm{~mL})$. Yellow crystals of complex $\mathbf{5}$ were obtained in low yield within two weeks.

$\left[\mathrm{NH}_{4}\right]_{6}\left[\mathrm{Ni}\left(\mathrm{H}_{2} \mathrm{O}\right)_{6}\right]_{2}\left[\left(\mathrm{UO}_{2}\right)_{4}(1,2-\mathrm{PDA})_{6}\right]_{2}\left[\left(\mathrm{UO}_{2}\right)_{4}(1,2-\mathrm{PDA})_{5}\left(\mathrm{H}_{2} \mathrm{O}\right)_{4}\right]$

(6). $1,2-$ Phenylenediacetic acid (20 mg, $0.10 \mathrm{mmol}), \mathrm{UO}_{2}\left(\mathrm{NO}_{3}\right)_{2} \cdot 6 \mathrm{H}_{2} \mathrm{O}(35 \mathrm{mg}, 0.07 \mathrm{mmol})$, and $\mathrm{Ni}\left(\mathrm{NO}_{3}\right)_{2} \cdot 6 \mathrm{H}_{2} \mathrm{O}(30 \mathrm{mg}, 0.10 \mathrm{mmol})$ were dissolved in water $(0.8 \mathrm{~mL})$ and acetonitrile $(0.2$ $\mathrm{mL})$. Yellow crystals of complex $\mathbf{6}$ were obtained in low yield within one month.

$\left[\mathrm{Cu}(\text { bipy })_{2}\left(\mathrm{NO}_{3}\right)\right]\left[\mathrm{UO}_{2}(1,2-\mathrm{PDA})\left(\mathrm{NO}_{3}\right)\right]$ (7). 1,2-Phenylenediacetic acid (20 mg, 0.10 $\mathrm{mmol}), \mathrm{UO}_{2}\left(\mathrm{NO}_{3}\right)_{2} \cdot 6 \mathrm{H}_{2} \mathrm{O}(35 \mathrm{mg}, 0.07 \mathrm{mmol}), \mathrm{Cu}\left(\mathrm{NO}_{3}\right)_{2} \cdot 2.5 \mathrm{H}_{2} \mathrm{O}(23 \mathrm{mg}, 0.10 \mathrm{mmol})$, and 2,2'-bipyridine (32 mg, $0.20 \mathrm{mmol})$ were dissolved in water $(0.7 \mathrm{~mL})$ and acetonitrile $(0.2 \mathrm{~mL})$. Blue-green crystals of complex 7 were obtained within two weeks $(21 \mathrm{mg}, 31 \%$ yield based on U). Anal. Calcd for $\mathrm{C}_{30} \mathrm{H}_{24} \mathrm{CuN}_{6} \mathrm{O}_{12} \mathrm{U}$ : C, 37.45; H, 2.51; N, 8.73. Found: C, 37.48; H, 2.58; N, $8.58 \%$. 
$\left[\mathrm{Ag}(\text { bipy })_{2}\right]\left[\mathrm{UO}_{2}(1,2-\mathrm{PDA})\left(\mathrm{NO}_{3}\right)\right]$ (8). 1,2-Phenylenediacetic acid (20 mg, $\left.0.10 \mathrm{mmol}\right)$, $\mathrm{UO}_{2}\left(\mathrm{NO}_{3}\right)_{2} \cdot 6 \mathrm{H}_{2} \mathrm{O}(35 \mathrm{mg}, 0.07 \mathrm{mmol}), \mathrm{AgNO}_{3}(17 \mathrm{mg}, 0.10 \mathrm{mmol})$, and 2,2'-bipyridine (32 $\mathrm{mg}, 0.20 \mathrm{mmol})$ were dissolved in water $(0.5 \mathrm{~mL})$ and acetonitrile $(0.2 \mathrm{~mL})$. Yellow crystals of complex 8 were obtained within three days (46 mg, 70\% yield based on U). Anal. Calcd for $\mathrm{C}_{30} \mathrm{H}_{24} \mathrm{AgN}_{5} \mathrm{O}_{9} \mathrm{U}: \mathrm{C}, 38.15 ; \mathrm{H}, 2.56 ; \mathrm{N}, 7.42$. Found: C, 37.98; H, 2.57; N, 7.51\%.

$\left[\mathrm{Ag}(\text { bipy })_{2}\right]\left[\mathrm{UO}_{2}(1,4-\mathrm{PDA})\left(\mathrm{NO}_{3}\right)\right]$ (9). 1,4-Phenylenediacetic acid (20 mg, $\left.0.10 \mathrm{mmol}\right)$, $\mathrm{UO}_{2}\left(\mathrm{NO}_{3}\right)_{2} \cdot 6 \mathrm{H}_{2} \mathrm{O}(35 \mathrm{mg}, 0.07 \mathrm{mmol}), \mathrm{AgNO}_{3}(17 \mathrm{mg}, 0.10 \mathrm{mmol})$, and 2,2'-bipyridine (32 $\mathrm{mg}, 0.20 \mathrm{mmol})$ were dissolved in water $(1.0 \mathrm{~mL})$ and acetonitrile $(0.2 \mathrm{~mL})$. Yellow crystals of complex 9 were obtained within four days (33 mg, 50\% yield based on U). Anal. Calcd for $\mathrm{C}_{30} \mathrm{H}_{24} \mathrm{AgN}_{5} \mathrm{O} 9 \mathrm{U}: \mathrm{C}, 38.15 ; \mathrm{H}, 2.56 ; \mathrm{N}, 7.42$. Found: C, 38.05; H, 2.60; N, 7.30\%.

$\left[\cup \mathrm{O}_{2} \mathrm{~Pb}(1,3-\mathrm{PDA})_{2}(\right.$ phen)] (10). 1,3-Phenylenediacetic acid (20 mg, $0.10 \mathrm{mmol})$, $\mathrm{UO}_{2}\left(\mathrm{NO}_{3}\right)_{2} \cdot 6 \mathrm{H}_{2} \mathrm{O}(35 \mathrm{mg}, 0.07 \mathrm{mmol}), \mathrm{Pb}\left(\mathrm{NO}_{3}\right)_{2}(33 \mathrm{mg}, 0.10 \mathrm{mmol})$, and 1,10-phenanthroline (18 mg, $0.10 \mathrm{mmol})$ were dissolved in water $(0.8 \mathrm{~mL})$ and DMF $(0.2 \mathrm{~mL})$. Yellow crystals of complex 10 were obtained within one week (39 mg, 75\% yield based on the acid). Anal. Calcd for $\mathrm{C}_{32} \mathrm{H}_{24} \mathrm{~N}_{2} \mathrm{O}_{10} \mathrm{PbU}$ : C, 36.89; H, 2.32; N, 2.69. Found: C, 35.92; H, 2.32; N, 2.79\%.

$\left[\left(\mathrm{UO}_{2}\right)_{2} \mathrm{~Pb}_{2}(1,4-\mathrm{PDA})_{3}(\mathrm{HCOO})_{2}(\text { phen })_{2}\right]$ (11). 1,4-Phenylenediacetic acid (20 mg, 0.10 mmol), $\mathrm{UO}_{2}\left(\mathrm{NO}_{3}\right)_{2} \cdot 6 \mathrm{H}_{2} \mathrm{O}(35 \mathrm{mg}, 0.07 \mathrm{mmol}), \mathrm{Pb}\left(\mathrm{NO}_{3}\right)_{2}(33 \mathrm{mg}, 0.10 \mathrm{mmol})$, and 1,10phenanthroline $(18 \mathrm{mg}, 0.10 \mathrm{mmol})$ were dissolved in water $(0.8 \mathrm{~mL})$ and DMF $(0.2 \mathrm{~mL})$. Yellow crystals of complex 11 were obtained in low yield within four days.

$\left[\mathrm{Zn}(\text { bipy })_{3}\right]\left[\left(\mathrm{UO}_{2}\right)_{2}(1,2-P D A)(1,4-P D A)_{2}\right] \cdot \mathrm{H}_{2} \mathrm{O}$ (12). 1,2-Phenylenediacetic acid (10 mg, $0.05 \mathrm{mmol}), 1,4-$ phenylenediacetic acid $(10 \mathrm{mg}, 0.05 \mathrm{mmol}), \mathrm{UO}_{2}\left(\mathrm{NO}_{3}\right)_{2} \cdot 6 \mathrm{H}_{2} \mathrm{O}(35 \mathrm{mg}, 0.07$ mmol), $\mathrm{Zn}\left(\mathrm{NO}_{3}\right)_{2} \cdot 6 \mathrm{H}_{2} \mathrm{O}(15 \mathrm{mg}, 0.05 \mathrm{mmol})$, and 2,2'-bipyridine (24 mg, $\left.0.15 \mathrm{mmol}\right)$ were dissolved in water $(0.6 \mathrm{~mL})$ and DMF $(0.2 \mathrm{~mL})$. Yellow crystals of complex 12 were obtained within three days (13 mg, 31\% yield based on 1,4- $\mathrm{H}_{2} \mathrm{PDA}$ ). Anal. Calcd for $\mathrm{C}_{60} \mathrm{H}_{50} \mathrm{~N}_{6} \mathrm{O}_{17} \mathrm{U}_{2} \mathrm{Zn}$ : C, 43.19; H, 3.02; N, 5.04. Found: C, 42.88; H, 2.99; N, 5.15\%. 
$\left[\mathrm{Cu}\left(\mathrm{R}, \mathrm{S}-\mathrm{Me}_{6} \mathrm{Cyclam}\right)\right]\left[\mathrm{UO}_{2}(1,3-\mathrm{PDA})\left(\mathrm{NO}_{3}\right)\right]_{2}$ (13). 1,3-Phenylenediacetic acid (20 mg, $0.10 \mathrm{mmol}), \mathrm{UO}_{2}\left(\mathrm{NO}_{3}\right)_{2} \cdot 6 \mathrm{H}_{2} \mathrm{O}(35 \mathrm{mg}, 0.07 \mathrm{mmol})$ and $\left[\mathrm{Cu}\left(R, S-\mathrm{Me}_{6} \mathrm{cyclam}\right)\left(\mathrm{NO}_{3}\right)_{2}\right](24 \mathrm{mg}$, $0.05 \mathrm{mmol})$ were dissolved in water $(0.8 \mathrm{~mL})$ and acetonitrile $(0.2 \mathrm{~mL})$. Orange crystals of complex 13 were obtained overnight (20 mg, 41\% yield based on U). Anal. Calcd for $\mathrm{C}_{36} \mathrm{H}_{52} \mathrm{CuN}_{6} \mathrm{O}_{18} \mathrm{U}_{2}: \mathrm{C}, 30.96 ; \mathrm{H}, 3.75 ; \mathrm{N}, 6.02$. Found: C, 31.58; H, 3.71; N, 6.06\%.

[Ni(cyclam)][(UO $\left.)_{2}(1,3-P D A)_{3}\right]$ (14). 1,3-Phenylenediacetic acid (20 mg, $\left.0.10 \mathrm{mmol}\right)$, $\mathrm{UO}_{2}\left(\mathrm{NO}_{3}\right)_{2} \cdot 6 \mathrm{H}_{2} \mathrm{O}(35 \mathrm{mg}, 0.07 \mathrm{mmol})$ and $\left[\mathrm{Ni}(\mathrm{cyclam})\left(\mathrm{NO}_{3}\right)_{2}\right](20 \mathrm{mg}, 0.05 \mathrm{mmol})$ were dissolved in water $(0.8 \mathrm{~mL})$ and acetonitrile $(0.2 \mathrm{~mL})$. Yellow crystals of complex 14 were obtained within one week ( $25 \mathrm{mg}$, $52 \%$ yield based on U). Anal. Calcd for $\mathrm{C}_{40} \mathrm{H}_{48} \mathrm{~N}_{4} \mathrm{NiO}_{16} \mathrm{U}_{2}$ : C, 34.93; H, 3.52; N, 4.07. Found: C, 34.87; H, 3.61; N, 4.27\%.

Crystallography. The data were collected at 100(2) K on a Nonius Kappa-CCD area detector diffractometer ${ }^{19}$ using graphite-monochromated Mo Ka radiation $(\lambda=0.71073 \AA)$. The crystals were introduced into glass capillaries with a protective coating of Paratone-N oil (Hampton Research). The unit cell parameters were determined from ten frames, then refined on all data. The data (combinations of $\varphi$ - and $\omega$-scans with a minimum redundancy of 4 for $90 \%$ of the reflections) were processed with HKL2000. ${ }^{20}$ Absorption effects were corrected empirically with the program SCALEPACK. ${ }^{20}$ The structures were solved by intrinsic phasing with SHELXT,${ }^{21}$ expanded by subsequent difference Fourier synthesis and refined by fullmatrix least-squares on $F^{2}$ with SHELXL, ${ }^{22}$ using the SHELXle graphical user interface. ${ }^{23}$ All non-hydrogen atoms were refined with anisotropic displacement parameters. When present, the hydrogen atoms bound to oxygen and nitrogen atoms were retrieved from difference Fourier maps (see below for details), and the carbon-bound hydrogen atoms were introduced at calculated positions. Except when mentioned below, all hydrogen atoms were treated as riding atoms with an isotropic displacement parameter equal to 1.2 times that of the parent atom (1.5 
for $\mathrm{CH}_{3}$, with optimized geometry). Crystal data and structure refinement parameters are given in Table 2. The molecular plots were drawn with ORTEP-3, ${ }^{24}$ and the polyhedral representations with VESTA. ${ }^{25}$ The topological analyses and nodal representations were made with TOPOS. ${ }^{26}$ Special details are as follows.

Complex 5. The hydrogen atoms bound to nitrogen atoms were found on a difference Fourier map and their positions were refined with restraints. The value of the refined Flack parameter is $-0.014(6)$.

Complex 6. Restraints on displacement parameters were applied for some oxygen atoms of water ligands. The hydrogen atoms bound to nitrogen atoms were found on a difference Fourier map, but not those of the water molecules. Large voids in the structure indicate the presence of other, unresolved solvent molecules.

Complex 10. The phen molecule is probably affected by disorder, but this could not be modelled properly and restraints on one bond length and displacement parameters had to be applied.

Complex 11. The oxygen atoms of the formate anion are disordered over two positions which were refined with occupancy parameters constrained to sum to unity and restraints on displacement parameters.

Complex 12. The solvent water molecule (O17) is disordered over two positions which were refined with occupancy parameters constrained to sum to unity, and its hydrogen atoms were not found.

Complex 13. The nitrate anion is disordered over two positions sharing the two coordinated oxygen atoms, which have been refined with occupancy parameters of 0.5 , restraints on bond lengths and imposed planar geometry.

Complex 14. The value of the refined Flack parameter, $0.368(11)$, is indicative of 2 component inversion twinning. 
Table 2. Crystal Data and Structure Refinement Details

\begin{tabular}{|c|c|c|c|c|c|c|c|}
\hline & 1 & 2 & 3 & 4 & 5 & 6 & 7 \\
\hline chemical formula & $\mathrm{C}_{22} \mathrm{H}_{19} \mathrm{~N}_{3} \mathrm{O}_{6} \mathrm{U}$ & $\mathrm{C}_{22} \mathrm{H}_{16} \mathrm{~N}_{2} \mathrm{O}_{6} \mathrm{U}$ & $\mathrm{C}_{20} \mathrm{H}_{16} \mathrm{~N}_{2} \mathrm{O}_{6} \mathrm{U}$ & $\mathrm{C}_{22} \mathrm{H}_{16} \mathrm{~N}_{2} \mathrm{O}_{6} \mathrm{U}$ & $\mathrm{C}_{50} \mathrm{H}_{65} \mathrm{~N}_{3} \mathrm{O}_{22} \mathrm{U}_{2}$ & $\mathrm{C}_{170} \mathrm{H}_{192} \mathrm{~N}_{6} \mathrm{Ni}_{2} \mathrm{O}_{108} \mathrm{U}_{12}$ & $\mathrm{C}_{30} \mathrm{H}_{24} \mathrm{CuN}_{6} \mathrm{O}_{12} \mathrm{U}$ \\
\hline$M\left(\mathrm{~g} \mathrm{~mol}^{-1}\right)$ & 659.43 & 642.40 & 618.38 & 642.40 & 1536.11 & 7021.06 & 962.12 \\
\hline cryst syst & triclinic & monoclinic & triclinic & triclinic & monoclinic & monoclinic & monoclinic \\
\hline space group & $P_{1}$ & $P 2_{1} / n$ & $P_{1}$ & $P_{1}$ & $P 2_{1}$ & $C 2 / c$ & $P 2_{1} / c$ \\
\hline$a(\AA)$ & $7.8708(5)$ & $7.7666(5)$ & $7.9849(6)$ & $8.7773(6)$ & $11.1842(4)$ & $41.6421(13)$ & $14.8168(9)$ \\
\hline$b(\AA)$ & $11.9112(8)$ & $16.2226(13)$ & $9.5215(10)$ & $9.9000(5)$ & $9.7396(2)$ & $21.9873(4)$ & $8.6290(4)$ \\
\hline$c(\AA)$ & $12.0180(11)$ & $16.2419(13)$ & $12.8367(14)$ & $11.9983(9)$ & $24.9076(9)$ & $28.0451(9)$ & $24.9157(14)$ \\
\hline$\alpha(\operatorname{deg})$ & $72.583(4)$ & 90 & $91.528(4)$ & $79.579(4)$ & 90 & 90 & 90 \\
\hline$\beta(\operatorname{deg})$ & $76.274(5)$ & $91.305(4)$ & $99.799(5)$ & $86.430(4)$ & $97.8714(17)$ & $92.537(2)$ & $99.977(4)$ \\
\hline$\gamma(\mathrm{deg})$ & $85.386(5)$ & 90 & $100.568(5)$ & $72.494(5)$ & 90 & 90 & 90 \\
\hline$V\left(\AA^{3}\right)$ & $1044.28(14)$ & $2045.9(3)$ & $943.71(16)$ & $977.87(11)$ & $2687.61(15)$ & $25652.9(12)$ & $3137.4(3)$ \\
\hline$Z$ & 2 & 4 & 2 & 2 & 2 & 4 & 4 \\
\hline reflns colled & 46720 & 90266 & 41778 & 41791 & 92072 & 242896 & 75937 \\
\hline indep reflns & 3969 & 3884 & 3593 & 3725 & 13798 & 24346 & 5950 \\
\hline obsd reflns $[I>2 \sigma(I)]$ & 3423 & 3065 & 3042 & 3093 & 12476 & 16202 & 3764 \\
\hline$R_{\text {int }}$ & 0.076 & 0.040 & 0.065 & 0.087 & 0.045 & 0.062 & 0.094 \\
\hline params refined & 290 & 280 & 262 & 280 & 702 & 1342 & 451 \\
\hline$R_{1}$ & 0.031 & 0.032 & 0.037 & 0.038 & 0.032 & 0.053 & 0.041 \\
\hline$w R_{2}$ & 0.059 & 0.068 & 0.085 & 0.079 & 0.067 & 0.145 & 0.071 \\
\hline$S$ & 0.962 & 1.049 & 1.041 & 0.984 & 0.989 & 1.047 & 0.922 \\
\hline$\Delta \rho_{\min }\left(\mathrm{e} \AA^{-3}\right)$ & -1.22 & -1.09 & -1.08 & -1.91 & -1.31 & -2.62 & -1.50 \\
\hline$\Delta \rho_{\max }\left(\mathrm{e} \AA^{-3}\right)$ & 0.70 & 0.59 & 1.68 & 1.48 & 1.43 & 2.59 & 1.39 \\
\hline
\end{tabular}

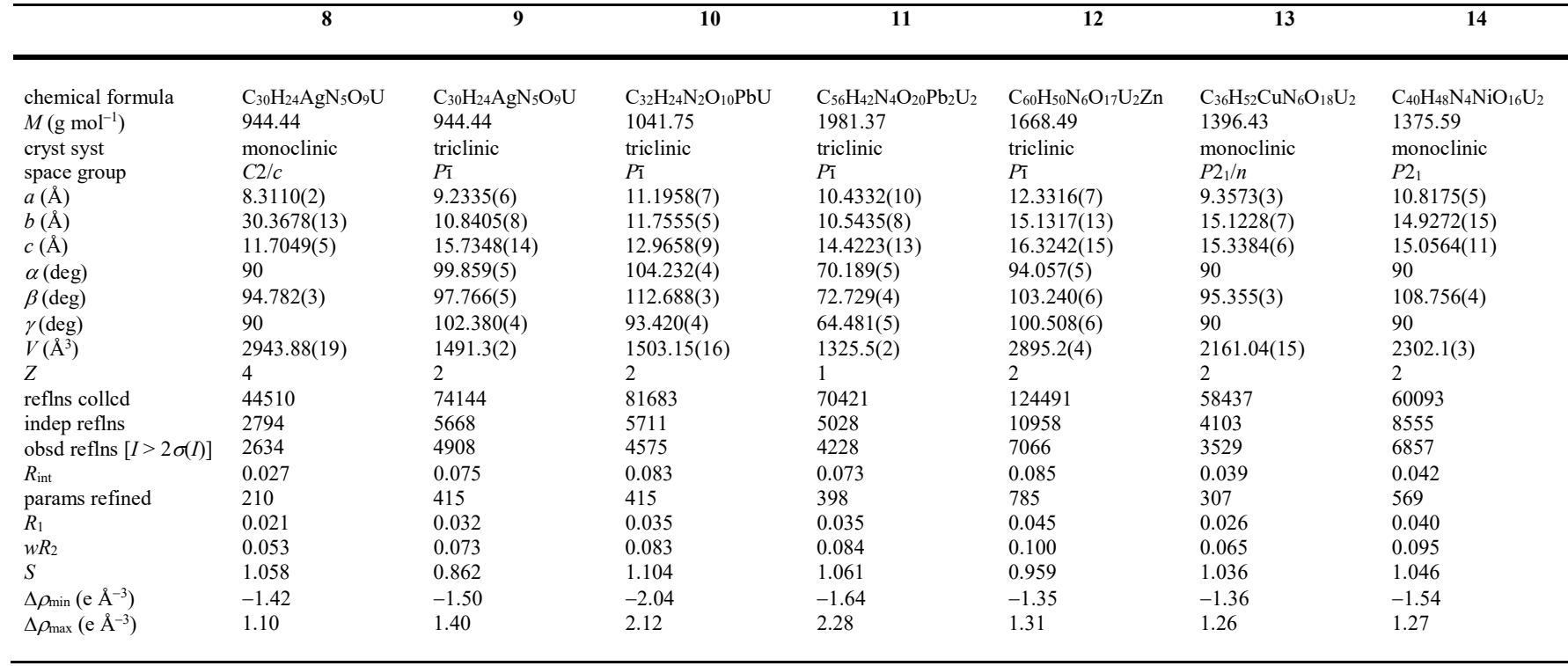

Luminescence Measurements. Emission spectra were recorded on solid samples using a Horiba-Jobin-Yvon IBH FL-322 Fluorolog 3 spectrometer equipped with a $450 \mathrm{~W}$ xenon arc lamp, double-grating excitation and emission monochromators $(2.1 \mathrm{~nm} / \mathrm{mm}$ of dispersion; 1200 grooves $/ \mathrm{mm}$ ) and a TBX-04 single photon-counting detector. The powdered compounds were pressed to the wall of a quartz tube, and the measurements were performed using the right-angle mode. An excitation wavelength of $420 \mathrm{~nm}$, a commonly used point although only part of a broad manifold, was used in all cases and the emission was monitored between 450 and 650 
nm. The quantum yield measurements were performed by using a Hamamatsu Quantaurus C11347 absolute photoluminescence quantum yield spectrometer and exciting the samples between 300 and $400 \mathrm{~nm}$.

\section{RESULTS AND DISCUSSION}

Synthesis. All complexes were synthesized under solvo-hydrothermal conditions, at a temperature of $140{ }^{\circ} \mathrm{C}$ (the crystals depositing at this temperature), and both acetonitrile and $N, N$-dimethylformamide (DMF) were systematically tested as organic cosolvents, their use allowing rapid and complete dissolution of the reactants. Overall, crystallization with acetonitrile cosolvent was more successful, since complexes 10-12 only were obtained with DMF. However, the organic cosolvent is rarely directly apparent in the final compound, with only two complexes ( $\mathbf{1}$ and $\mathbf{5})$ crystallizing as acetonitrile solvates, while complex $\mathbf{6}$ contains ammonium ions presumably derived from acetonitrile hydrolysis and complex $\mathbf{1 1}$ incorporates formate ligands generated by DMF hydrolysis. The relatively slow hydrolysis reaction of acetonitrile is presumably one factor contributing to the long reaction period required for deposition of complex 6. Given the lability of the metal ions present in all the syntheses, however, it is clear that crystallisation of the complexes is the rate determining step. So as to favour the occurrence of structure-directing effects exerted by counterions or additional cations on an anionic uranyl complex, the uranium/dicarboxylate ligand ratio was 7:10 in all cases except for $\mathbf{3}$ and $\mathbf{4}$ (which were intended to include neutral bipy or phen coligands). However, only in compounds $\mathbf{5 , 1 1}, \mathbf{1 2}$ and $\mathbf{1 4}$ is the expected 2:3 ratio retained, a 1:1 ratio being found in $\mathbf{1}-\mathbf{4}, \mathbf{7}-\mathbf{9}$ and $\mathbf{1 3}, 1: 2$ in $\mathbf{1 0}$, and a much more unusual 12:17 ratio in $\mathbf{6}$. When present, the counterions are separate from the anionic uranyl-containing polymeric species, but for lead(II) which is part of the polymer in complexes $\mathbf{1 0}$ and $\mathbf{1 1 .}$ 
Crystal Structures. The geometry of the uranyl cation and its environment in the present carboxylate complexes generally departing little from its usual characteristics, it will be only briefly summarized prior to the description of the complexes themselves. In all complexes 1-14, the uranyl cation is almost linear $\left[\mathrm{O}=\mathrm{U}=\mathrm{O}\right.$ angle in the range of $\left.176.3(3)-179.8(5)^{\circ}\right]$ with unexceptional $\mathrm{U}=\mathrm{O}$ bond lengths in the range of $1.754(8)-1.782(11) \AA$. The uranium coordination environment is hexagonal bipyramidal in all cases except for complexes $\mathbf{1 1}$ and 14, in which it is pentagonal bipyramidal. Due to bipy or phen coordination, the hexagonal bipyramidal environment in complexes 1-4 is quite distorted and the complex unit is chiral (see below). The U-O(carboxylato) bond lengths are in the ranges 2.398(3)-2.509(6) Å for chelating groups and 2.303(5)-2.391(10) ̊̊ for monodentate groups, and warrant no particular comment.

The complexes $\left[\mathrm{UO}_{2}(1,2-\mathrm{PDA})(\mathrm{bipy})\right] \cdot \mathrm{CH}_{3} \mathrm{CN} \quad$ (1), $\left[\mathrm{UO}_{2}(1,2-\mathrm{PDA})(\mathrm{phen})\right]$ (2), [UO 2 (1,3-PDA)(bipy)] (3), and [UO $2(1,3-\mathrm{PDA})(\mathrm{phen})]$ (4) are closely related, with in all cases the unique uranyl cation being chelated by two carboxylate groups and one bipy or phen molecule (Figure 1). As in other examples of this arrangement, the bipy or phen ligands are tilted with respect to the equatorial plane, with dihedral angles between the bipy/phen molecule and the average $\mathrm{UO}_{4}$ plane of $38.68(10), 36.24(6), 38.02(7)$ and $24.14(19)^{\circ}$ for $\mathbf{1}-\mathbf{4}$, respectively. These angles are within the range previously found in uranyl complexes with longchain aliphatic $\alpha, \omega$-dicarboxylates, ${ }^{27}$ with the same trend for the tilting to be more pronounced for bipy ligands. This distortion makes the uranium environment chiral, with no resolution of enantiomers occurring since the four complexes crystallize in centrosymmetric space groups. Ribbon-like, homochiral 1D coordination polymers are formed in all cases (parallel to [100] in $\mathbf{1},[010]$ in 2, [110] in 3 and [001] in 4), the finer details of which depend on the shape of the dicarboxylate ligand and the nature of the $N$-donor. In complexes $\mathbf{1}, \mathbf{3}$ and $\mathbf{4}$, the bipy or phen ligands are all located on one edge of the ribbon, the successive motifs being generated by translations, while in $\mathbf{2}$ they are alternately located on either edge and related by 2 -fold rotations. 

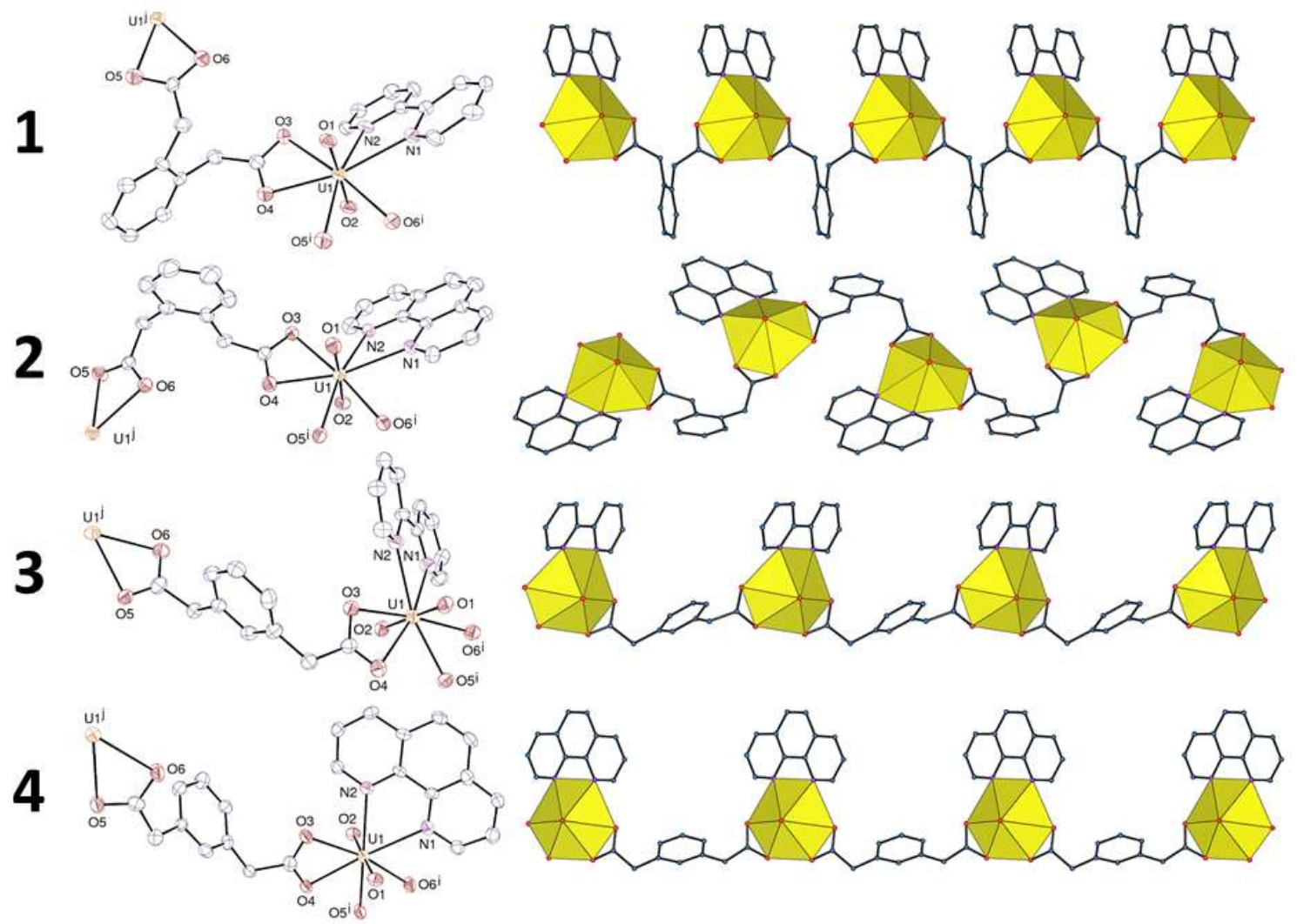

Figure 1. Left: Views of compounds 1-4 with displacement ellipsoids drawn at the 50\% probability level. Solvent molecules and hydrogen atoms are omitted. Symmetry codes: $\mathbf{1} \mathrm{i}=x+1, y, z ; \mathbf{j}=x-1, y, z ; \mathbf{2} \mathrm{i}=3 / 2-x, y+1 / 2$, $3 / 2-z ; \mathrm{j}=3 / 2-x, y-1 / 2,3 / 2-z ; \mathbf{3} \mathrm{i}=x-1, y-1, z ; \mathrm{j}=x+1, y+1, z ; \mathbf{4} \mathrm{i}=x, y, z-1 ; \mathrm{j}=x, y, z+1$. Right: Views of the 1D coordination polymers with uranium coordination polyhedra colored yellow.

These two types of arrangements were previously found in uranyl complexes with long-chain aliphatic $\alpha, \omega$-dicarboxylates, in which the second geometry was however more frequent. ${ }^{27}$ In complex $\mathbf{1}$, the 1,2-PDA ${ }^{2-}$ ligand is close to $C_{2}$ symmetry and it has its two carboxylate groups pointing to different sides of the aromatic ring, so that the latter is strongly tilted with respect to the chain axis, as is the bipy ligand. In contrast, one of the carboxylate groups in complex $\mathbf{2}$ is pointing toward one side of the aromatic plane while the other is directed sideways and straddles the plane of the aromatic ring, while the aromatic ring itself lies nearly parallel to the chain axis. As a consequence of the different orientation of the carboxylate groups, the U...U separation along the chain is shorter in $\mathbf{1}$ [7.8708(5) $\AA]$ than in $\mathbf{2}$ [8.7570(7) $\AA]$. The orientation of the two carboxylate groups of the 1,3-PDA ${ }^{2-}$ ligand in $\mathbf{3}$ is analogous to that in $\mathbf{2}$, but the 
more elongated shape of the molecule results in a larger U...U separation of 11.2486(10) $\AA$. The 1,3-PDA ${ }^{2-}$ ligand is even more elongated in $\mathbf{4}$, and the U..U separation slightly larger, at 11.9983(9) Å. The chains in $\mathbf{1}$ are arranged in twos of opposite chirality to form pseudo-tubular assemblies, these being stacked so as to form layers parallel to (001), as shown in Figure 2. Analysis of short contacts with PLATON ${ }^{28}$ reveals two possible parallel-displaced $\pi$-stacking
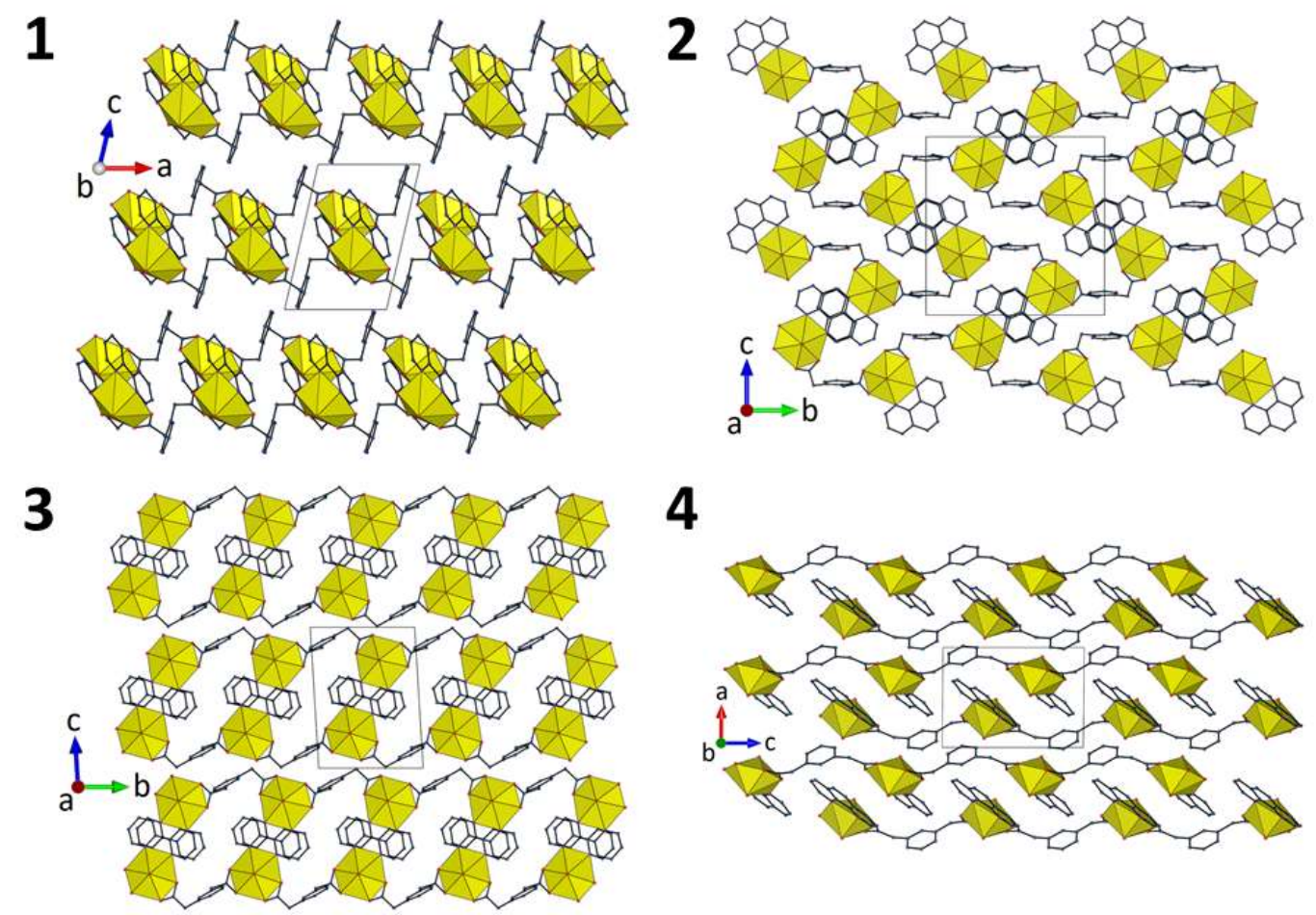

Figure 2. Views of the packing in compounds 1-4 with uranium coordination polyhedra colored yellow. Solvent molecules and hydrogen atoms are omitted.

interactions involving bipy molecules pertaining to adjacent dimers in the sheets [centroid $\cdots$ centroid distances 3.693(3) and 3.926(3) $\AA$, dihedral angles 0 and $11.3(3)^{\circ}$ ]. However, examination of the Hirshfeld surface (HS) ${ }^{29}$ calculated with CrystalExplorer (version $3.1)^{30}$ shows that these contacts are not stronger than dispersion interactions. $\mathrm{CH} \cdots \mathrm{O}$ hydrogen bonds $\mathrm{s}^{31,32}$ involving oxo and carboxylato groups are present as well, and they appear clearly on the HS $\left[\mathrm{C} \cdots \mathrm{O} 2.861(7)-3.494(6) \AA, \mathrm{C}-\mathrm{H} \cdots \mathrm{O} 112-174^{\circ}\right]$. Such hydrogen bonds are very commonly found in uranyl carboxylate complexes, and in particular in all the present 
compounds (and their occurrence will not be further mentioned). The chains in $\mathbf{2}$ are arranged in sheets parallel to (101), with here also contacts indicative of at best weak parallel-displaced $\pi$-stacking interactions involving phen molecules [centroid $\cdots$ centroid distances $3.740(3)-$ 4.042(3) $\AA$, dihedral angles $\left.0-4.8(3)^{\circ}\right]$. The packing in 3 can be viewed as containing double layers parallel to (001), with the bipy molecules located inside and facing each other so that, here also, weak $\pi$-stacking interactions may be present [centroid $\cdots$ centroid distances $3.774(4)$ and 3.935(4) $\AA$, dihedral angles $11.0(4)$ and $0^{\circ}$ ], as well as intersheet interactions involving the aromatic rings of the 1,3-PDA ${ }^{2-}$ ligands [centroid $\cdots$ centroid distance 3.566(4) $\AA$, dihedral angle $0^{\circ}$ ]. A similar arrangement is found in $\mathbf{4}$, with double sheets parallel to (100) and interactions

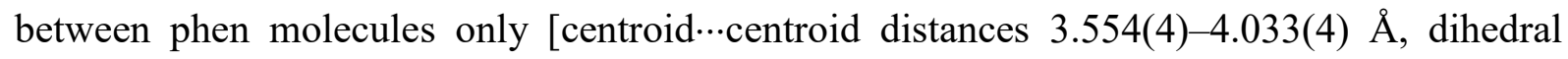
angles $0-2.6(3)^{\circ}$. The Kitaigorodski packing indexes (KPIs) calculated with PLATON, ${ }^{28}$ are $0.73,0.69,0.71$ and 0.72 for $\mathbf{1}-\mathbf{4}$, respectively, these values being indicative of compact packings with no significant porosity.

In the complex incorporating the diprotonated [2.2.2]cryptand as a counterion, $\left[\mathrm{H}_{2}-\right.$ 2.2.2] $\left[\left(\mathrm{UO}_{2}\right)_{2}(1,2-\mathrm{PDA})_{3}\right] \cdot \mathrm{CH}_{3} \mathrm{CN}(5)$, the two independent uranyl ions are each chelated by three carboxylate groups (Figure 3). The 1,2-PDA ${ }^{2-}$ ligand containing O5 to O8 has the conformation found in $\mathbf{1}$, with the two carboxylate groups directed on either side of the aromatic ring, while the other two ligands have one carboxylate group directed sideways and straddling the aromatic plane, as in $\mathbf{2}$. The 1D polymer formed, directed along [010], is ladder-shaped, as that previously found in $\left[\mathrm{Zn}(\mathrm{phen})_{3}\right]\left[\left(\mathrm{UO}_{2}\right)_{2}(1,2-\mathrm{PDA})_{3}\right] \cdot 7 \mathrm{H}_{2} \mathrm{O},{ }^{16}$ but, instead of having a tubelike geometry as the latter, it is ribbon-shaped, with the aromatic rings of the ligands protruding outside, giving the ribbon a slightly curved section. The different polymer shapes in these two compounds appear to be a direct result of the distinct counterion geometries. The packing displays channels in which the $\left[\mathrm{H}_{2}-2.2 .2\right]^{2+}$ counterions are located. The ammonium protons are directed inside the cryptand cavity and involved in intramolecular hydrogen 
bonding. No $\pi$-stacking interaction is present and the KPI, with solvent included, amounts to 0.71 .
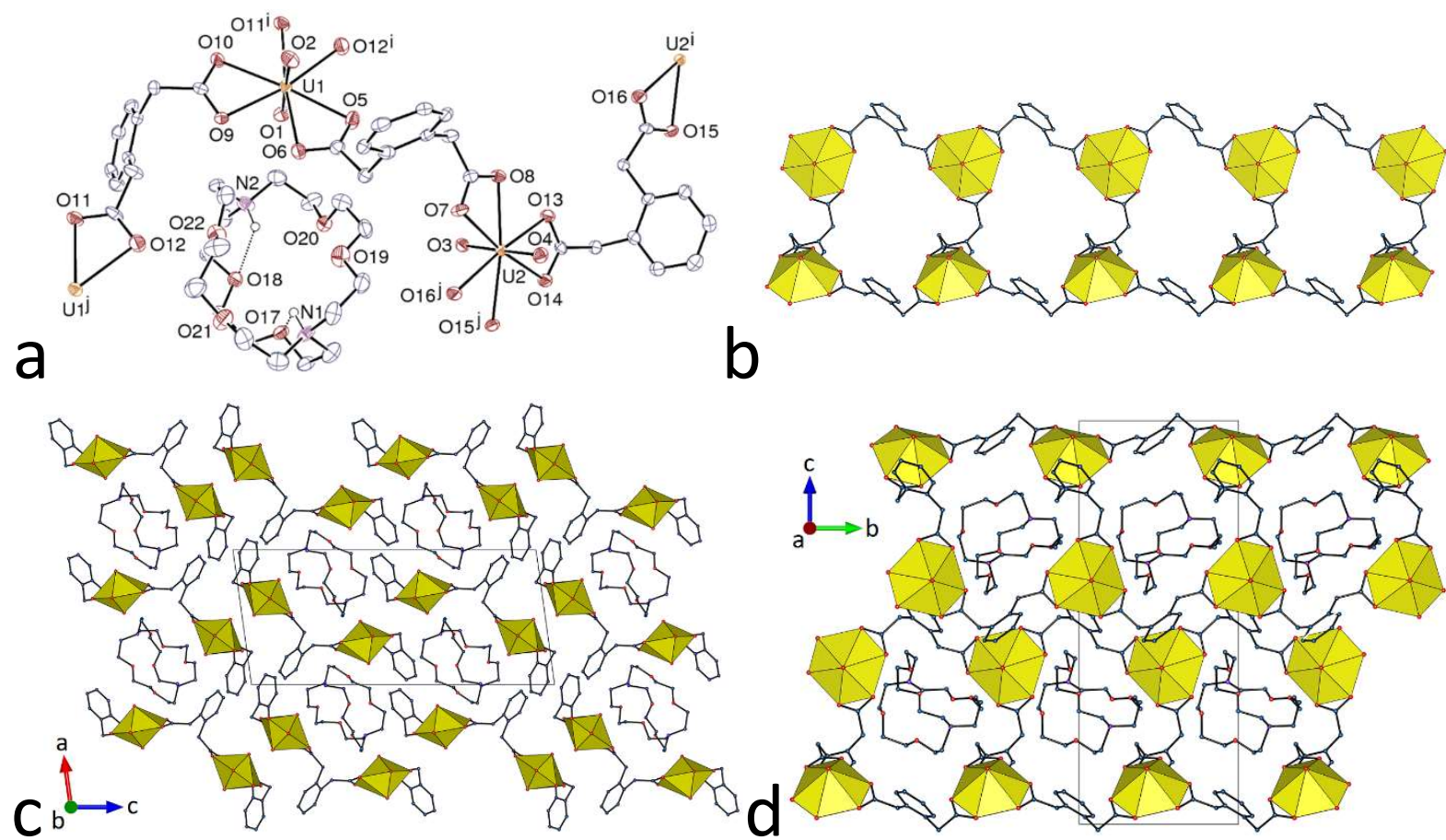

Figure 3. (a) View of compound 5. Displacement ellipsoids are drawn at the 50\% probability level. Solvent molecules and carbon-bound hydrogen atoms are omitted. Symmetry codes: $\mathrm{i}=x, y+1, z ; \mathrm{j}=x, y-1, z$. (b) The 1D polymer viewed down the $a$ axis. (c) and (d) Two views of the packing with solvent molecules and hydrogen atoms omitted.

The complex $\left[\mathrm{NH}_{4}\right]_{6}\left[\mathrm{Ni}\left(\mathrm{H}_{2} \mathrm{O}\right)_{6}\right]_{2}\left[\left(\mathrm{UO}_{2}\right)_{4}(1,2-\mathrm{PDA})_{6}\right]_{2}\left[\left(\mathrm{UO}_{2}\right)_{4}(1,2-\mathrm{PDA})_{5}\left(\mathrm{H}_{2} \mathrm{O}\right)_{4}\right]$ (6) contains two separate anionic uranyl complexes, the first being polymeric and containing atoms U1 to U4, and the second a tetranuclear discrete species containing U5 and U6 (Figure 4). All uranium atoms are chelated by three carboxylate groups, but for U6, for which one of them is replaced by two terminal water molecules. The six independent 1,2-PDA ${ }^{2-}$ ligands in the polymeric subunit can be separated into two groups: two are in the same conformation as found in $\mathbf{1}$, with the two carboxylate groups pointing on different faces of the aromatic ring, while the other four display carboxylate groups pointing on the same side of the ring and can thus be considered as convergent ligands. The latter ligands form saddle-shaped $\left(\mathrm{UO}_{2}\right)_{2}(1,2-\mathrm{PDA})_{2}$ 
dimers (18-membered metallacycles) which are connected to one another by the divergent ligands to form a zigzag $1 \mathrm{D}$ chain directed along [010], in which the U-turns bring the linear sections (containing two dimers) nearly perpendicular to the chain axis (and thus parallel to one another). These chains are in fact helical (although the helix is very flattened) and they are arranged in sheets parallel to (100), adjacent chains having alternate chiralities; these sheets
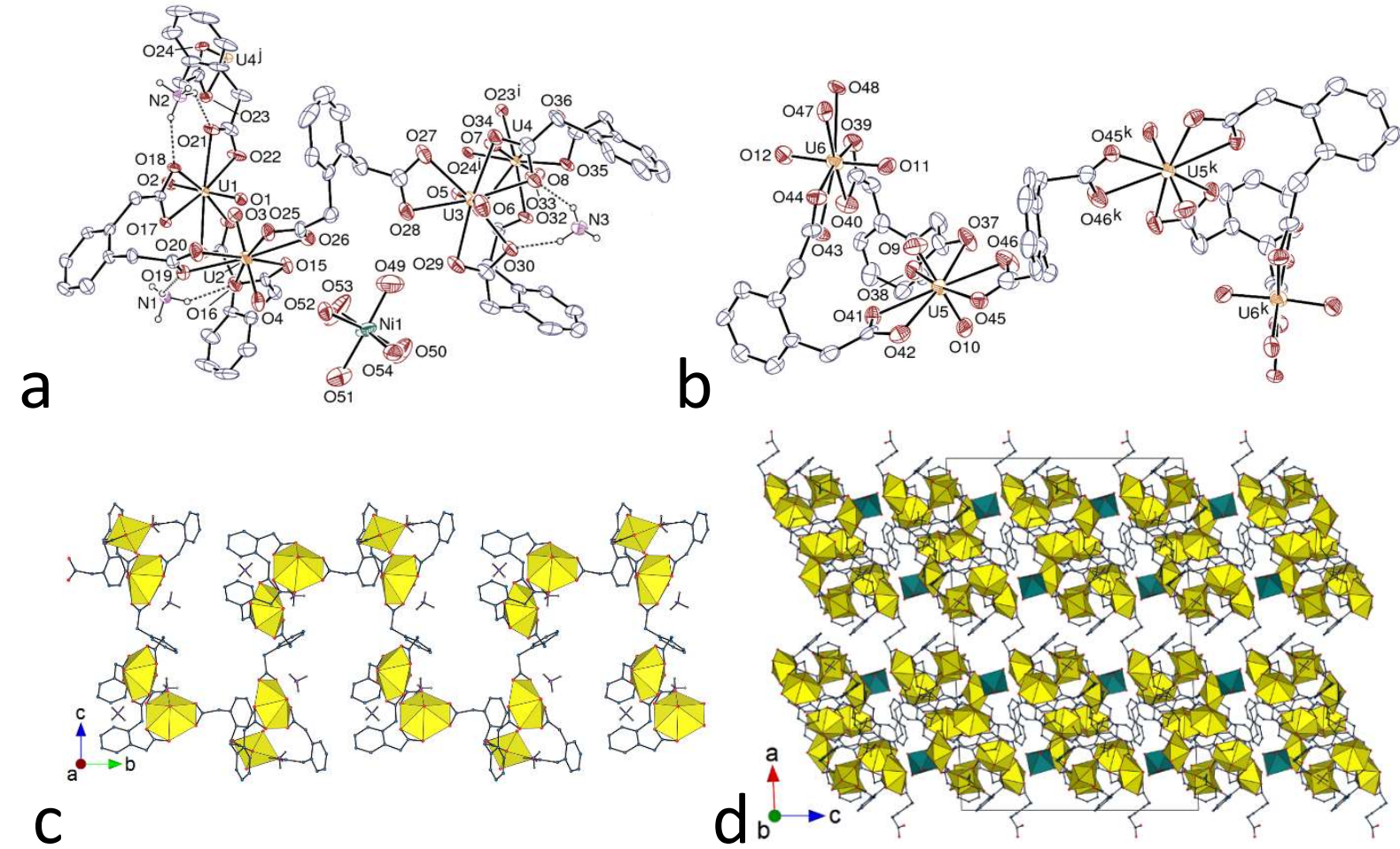

C

Figure 4. (a) and (b) Views of the two independent anionic complex units in compound 6. Displacement ellipsoids are drawn at the $30 \%$ probability level. Carbon-bound hydrogen atoms are omitted and hydrogen bonds are shown as dashed lines. Symmetry codes: $\mathrm{i}=1 / 2-x, y-1 / 2,1 / 2-z ; \mathrm{j}=1 / 2-x, y+1 / 2,1 / 2-z ; \mathrm{k}=1-x, y, 3 / 2-z$. (c) View of the helical 1D polymer. (d) View of the packing with uranium coordination polyhedra in yellow and those of nickel in green.

contain the $\left[\mathrm{Ni}\left(\mathrm{H}_{2} \mathrm{O}\right)_{6}\right]^{2+}$ counterions. The tetranuclear unit $\left[\left(\mathrm{UO}_{2}\right)_{4}(1,2-\mathrm{PDA})_{5}\left(\mathrm{H}_{2} \mathrm{O}\right)_{4}\right]^{2-}$ can be regarded as a fragment of the polymer obtained by excising a unit with all four inequivalent uranium atoms present and then removing the two terminal 1,2-PDA ${ }^{2-}$ ligands of chiral conformation, leaving just one to link the two metallacyclic units. These oligomers alternate in chirality within columns parallel to [001]. While the lack of locations for the hydrogen atoms 
of the water molecules coordinated to U6 (a lack which also aplies to the hydrogen atoms of the water molecules on $\mathrm{Ni}^{\mathrm{II}}$; see Experimental Section) renders interpretation of their hydrogen bonding interactions uncertain, it may be noted that each of the three inequivalent ammonium cations is involved in four or six $\mathrm{NH} \cdots \mathrm{O}$ bonds and these serve, in the case of the cation incorporating N1, to link together polymer chains of opposite chirality and, in the cases of N2 and N3 to link the oligomers to polymer chains of opposite chirality. It is notable that all three ammonium ions are located within the cleft defined by the two aromatic rings of a saddleshaped dimer. The exact array of interactions involving the $\left[\mathrm{Ni}\left(\mathrm{H}_{2} \mathrm{O}\right)_{6}\right]^{2+}$ cations is difficult to define but, on the basis of $\mathrm{O} \cdots \mathrm{O}$ separations, this cation also appears to be involved in linking polymer chains as well as polymer and oligomer chains. The packing does not display any $\pi$ stacking interaction. The low KPI of this structure (0.55) indicates the presence of voids probably containing disordered solvent molecules.

Given the extremely common use of uranyl nitrate as a reactant in uranyl complex syntheses and the fact that nitrate is a good (usually chelating) ligand for uranyl ion, it is somewhat surprising that it appears relatively infrequently in the crystalline products of solvothermal reactions. However, the three complexes $\left[\mathrm{Cu}(\text { bipy })_{2}\left(\mathrm{NO}_{3}\right)\right]\left[\mathrm{UO}_{2}(1,2-\right.$ $\left.\mathrm{PDA})\left(\mathrm{NO}_{3}\right)\right] \quad(7), \quad\left[\mathrm{Ag}(\text { bipy })_{2}\right]\left[\mathrm{UO}_{2}(1,2-\mathrm{PDA})\left(\mathrm{NO}_{3}\right)\right] \quad(\mathbf{8}), \quad$ and $\quad\left[\mathrm{Ag}(\text { bipy })_{2}\right]\left[\mathrm{UO}_{2}(1,4-\right.$ PDA) $\left(\mathrm{NO}_{3}\right)$ ] (9) present the common feature of retaining a chelating nitrate anion in the uranium coordination sphere, an obvious drawback for the increase of polymer periodicity. In all cases, the uranyl cation is also chelated by two carboxylate groups, though with an equatorial $\mathrm{O}_{6}$ garland which is much less distorted from planarity than the $\mathrm{O}_{4} \mathrm{~N}_{2}$ garland in $\mathbf{1}-\mathbf{4}$, resulting in the formation of 1D polymers directed along [010], [100] and [211], respectively (Figures 5-7). The 1,2-PDA ${ }^{2-}$ ligand in both 7 and $\mathbf{8}$ has the pseudo- $C_{2}$ conformation found in $\mathbf{1}$, and the homochiral 1D polymers, with all dicarboxylate ligands at one edge and the nitrate ions at the other, are similar to that found in $\mathbf{1}$. Note that with two elements of chirality, ligand 

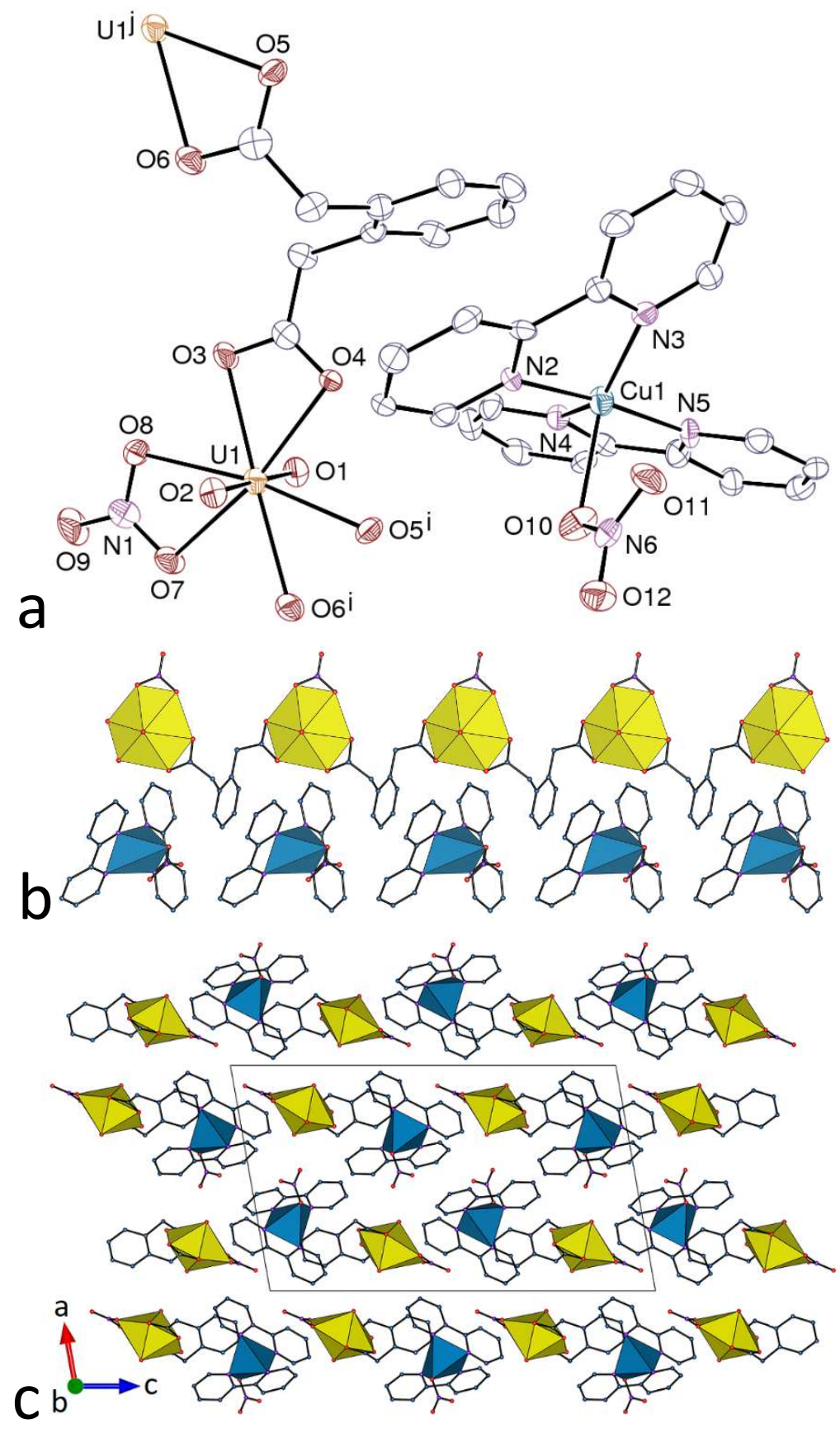

Figure 5. (a) View of compound 7. Displacement ellipsoids are drawn at the $50 \%$ probability level. Symmetry codes: $\mathrm{i}=x, y-1, z ; \mathrm{j}=x, y+1, z$. (b) View of the 1D polymer and the associated counterions. (c) View of the packing with chains viewed end-on. Uranium coordination polyhedra are yellow and those of copper blue. Hydrogen atoms are omitted in all views. 

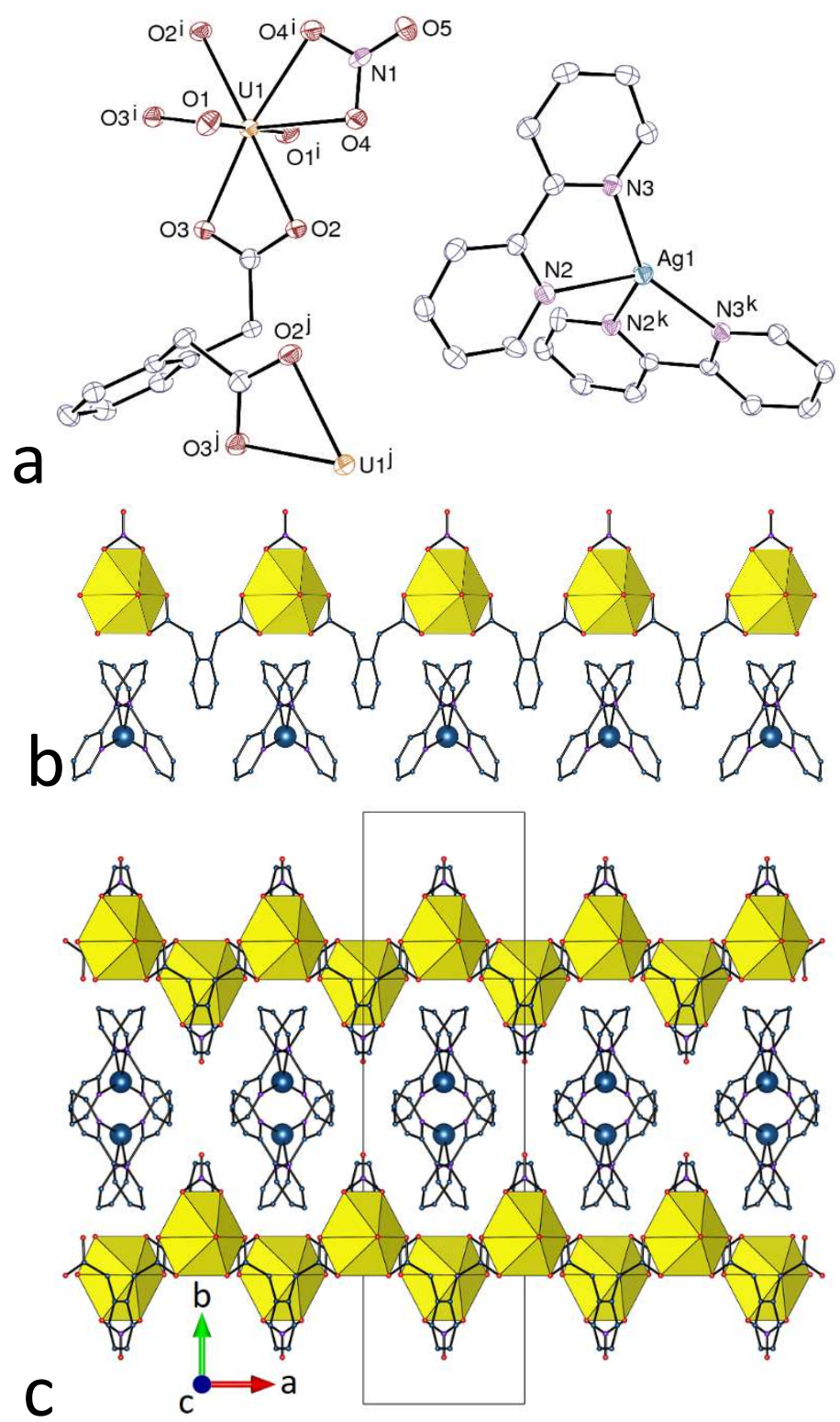

Figure 6. (a) View of compound 8. Displacement ellipsoids are drawn at the $50 \%$ probability level. Symmetry codes: $\mathrm{i}=2-x, y, 1 / 2-z ; \mathrm{j}=1-x, y, 1 / 2-z ; \mathrm{k}=1-x, y, 3 / 2-z$. (b) View of the $1 \mathrm{D}$ polymer and the associated counterions. (c) View of the packing. Uranium coordination polyhedra are yellow and silver atoms are shown as blue spheres. Hydrogen atoms are omitted in all views.

conformation and strand helicity, diastereoisomerism might be anticipated but in all the present cases only one ligand enantiomer is associated with one helical form. Complexes $\mathbf{7}$ and $\mathbf{8}$ crystallize in centrosymmetric space groups, so that both enantiomers of the polymer chains as well as both enantiomers of the chiral (in the solid state) complex cations are present. The chains in 7 are arranged into sheets parallel to (100), which contain also the counterions protruding on 


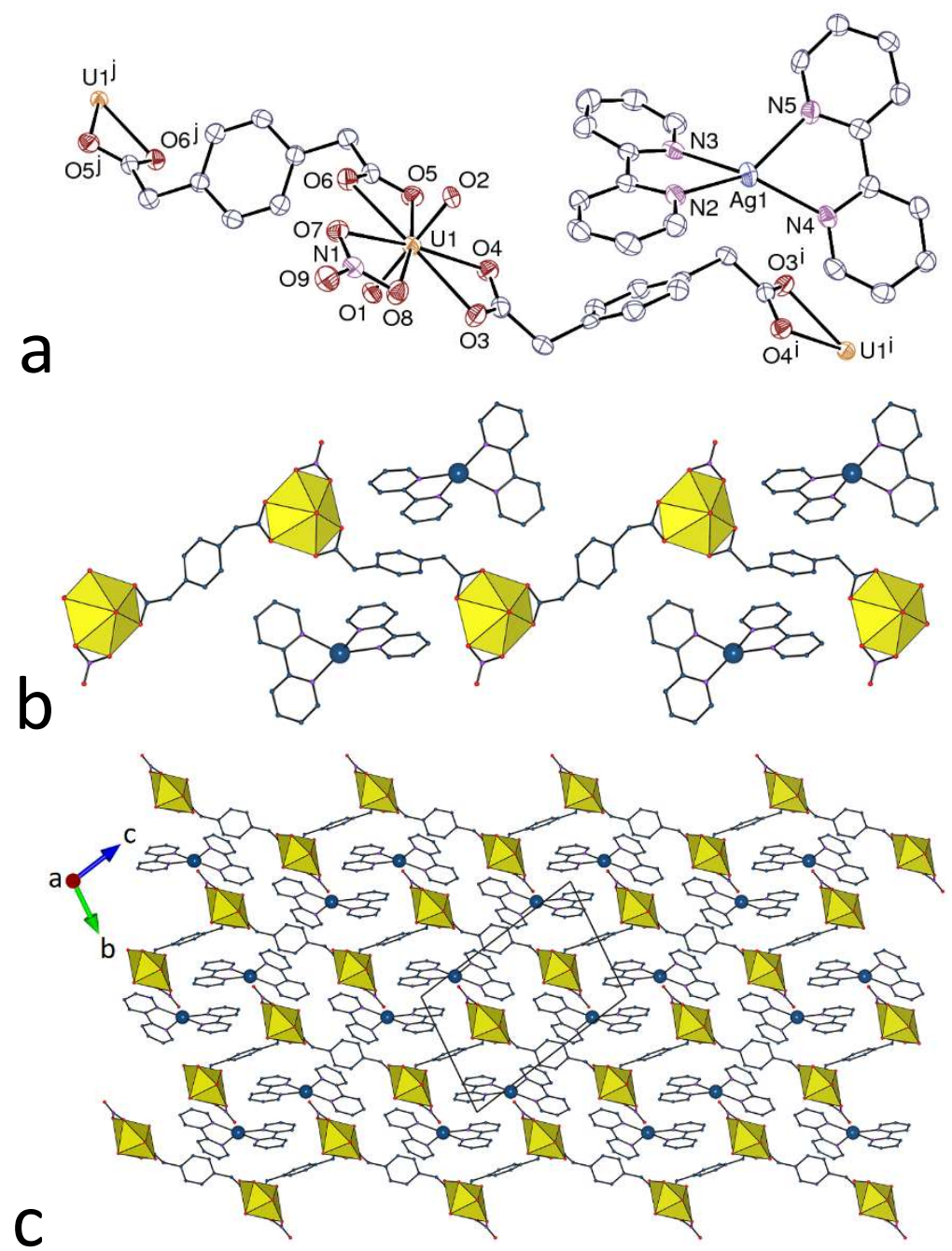

Figure 7. (a) View of compound 9. Displacement ellipsoids are drawn at the 50\% probability level. Symmetry codes: $\mathrm{i}=2-x, 2-y, 1-z ; \mathrm{j}=-x, 1-y,-z$. (b) View of the $1 \mathrm{D}$ polymer and the associated counterions. (c) View of the packing. Uranium coordination polyhedra are yellow and silver atoms are shown as blue spheres. Hydrogen atoms are omitted in all views.

one face, and these sheets are packed in twos, facing each other through countercations possibly

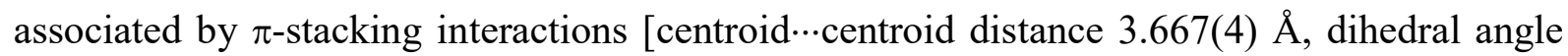
$\left.0^{\circ}\right]$; other intrasheet interactions involve aromatic groups from both 1,2-PDA ${ }^{2-}$ and bipy. The nitrate anion in $\left[\mathrm{Cu}(\mathrm{bipy})_{2}\left(\mathrm{NO}_{3}\right)\right]^{+}$is monodentate $[\mathrm{Cu} 1-\mathrm{O} 102.289(5) \AA$, the other contact, Cu1-O11 2.680(5) $\AA$ indicates at best a much weaker interaction], and the copper(II) cation environment is distorted trigonal bipyramidal with atoms $\mathrm{N} 2$ and $\mathrm{N} 5$ in axial positions; although uncommon, this cation has previously been described ${ }^{33-35}$ In complex 8 , the chains are arranged 
into sheets parallel to $(010)$ so that nitrate groups point alternately on either side, and these sheets are separated by layers of $\left[\operatorname{Ag}(\text { bipy })_{2}\right]^{+}$counterions, which have a flattened tetrahedral geometry and display possible parallel-displaced $\pi$-stacking interactions [centroid $\cdots$ centroid distance $3.7450(18) \AA$, dihedral angle $0^{\circ}$ ]. As in complexes 7 and $\mathbf{8}$, the presence of a singly charged heterocation appears to favour formation of singly charged monomer units in complex 9. The centrosymmetric, extended 1,4-PDA ${ }^{2-}$ ligands in 9 have one carboxylate group on each side of the aromatic ring, and the helical chains, with nitrate anions pointing alternately on the two edges, are arranged in sheets parallel to $(01 \overline{1})$, between which the counterions are located. Here also, possible parallel-displaced $\pi$-stacking interactions involving both $1,4-\mathrm{PDA}^{2-}$ and

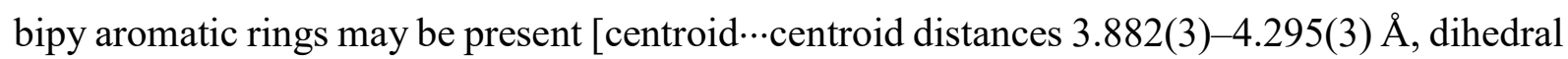
angles $0-29.4(2)^{\circ}$ ]. With KPIs of $\sim 0.71$, the packings in complexes $7-9$ do not display significant free space.

Two complexes in this series, with the 1,3- and 1,4-PDA ${ }^{2-}$ ligands, contain the $\mathrm{Pb}(\text { phen })^{2+}$ moiety as part of the neutral polymeric assembly, as is generally the case with this group or with $\mathrm{Pb}(\text { bipy })^{2+}$ due to the affinity of $\mathrm{Pb}^{2+}$ for carboxylate donors which prevents its separation as a purely $N$-chelated complex. ${ }^{36-39} \mathrm{In}$ complex $\left[\mathrm{UO}_{2} \mathrm{~Pb}(1,3-\mathrm{PDA})_{2}\right.$ (phen) $](\mathbf{1 0})$, the unique uranyl cation is chelated by three carboxylate groups, while lead(II) is chelated by one carboxylate and phen, and is also bound to two more carboxylate oxygen atoms and the uranyl oxo atom $\mathrm{O} 1$ (Figure 8 ). The $\mathrm{Pb}-\mathrm{O}$ bond lengths are 2.456(4) and 2.485(5) $\AA$ for the chelating carboxylate, and $2.765(5)$ and $2.777(4) \AA$ for the single carboxylate donors, the latter from carboxylate groups bound to both uranium and lead in $\mu_{2}-\kappa^{2} O, O^{\prime}: \kappa^{1} O^{\prime}$ mode. These bond lengths are unexceptional, as are the $\mathrm{Pb}-\mathrm{N}$ ones [2.476(6) and 2.535(7) $\AA$ ]. The $\mathrm{Pb}-\mathrm{O}$ (oxo) bond length of 2.921(4) $\AA$ is comparable to those of 2.999(4), 3.007(2) and 3.176(5) $\AA$ found in complexes with tetrahydrofurantetracarboxylate, ${ }^{40} 2,6$-pyridinedicarboxylate, ${ }^{38}$ and $1,3,5-$ benzenetriacetate, ${ }^{36}$ respectively. However, $\mathrm{Pb}-\mathrm{O}$ (uranyl) bond lengths as short as $\sim 2.5 \AA$ have 

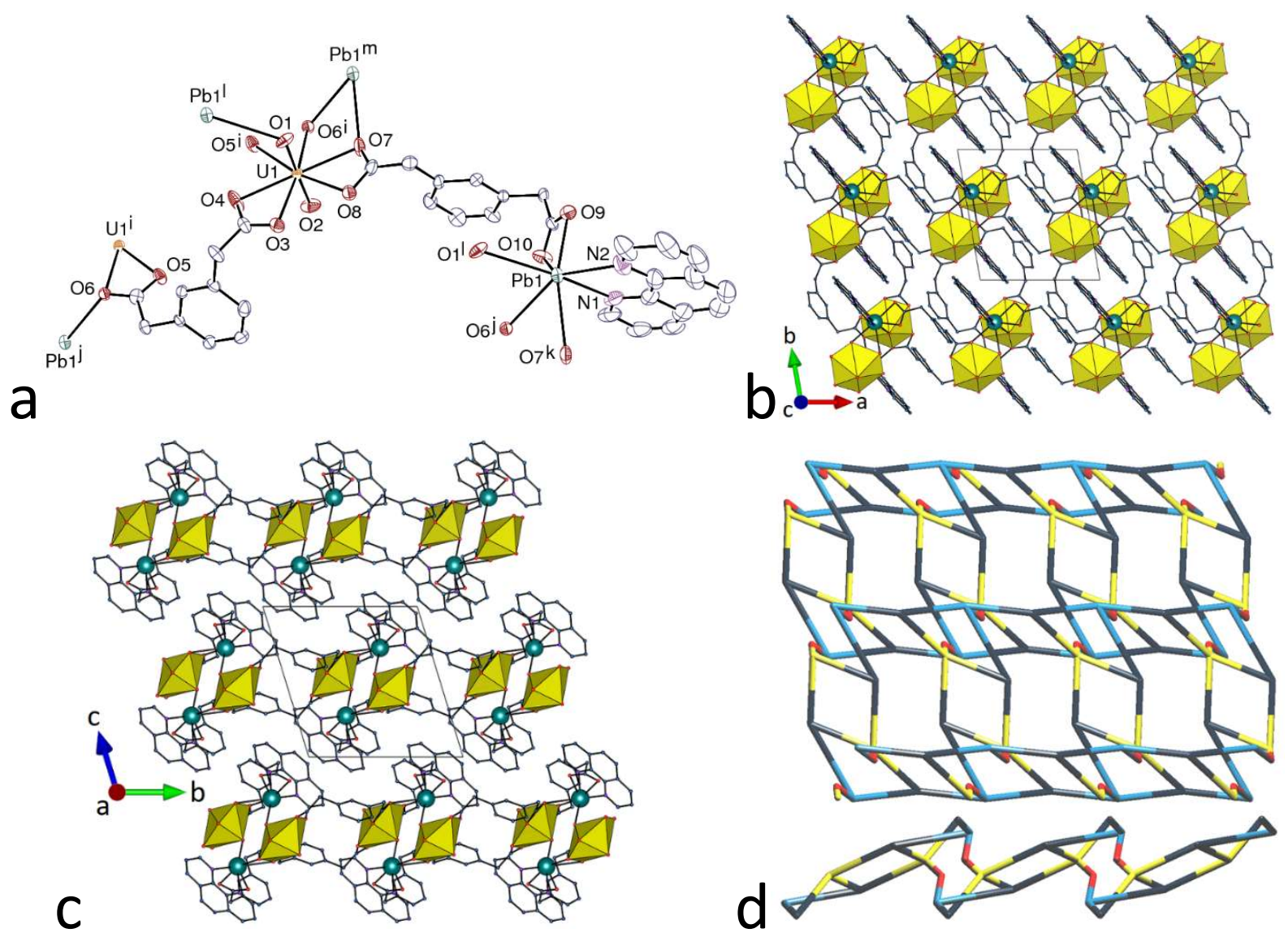

Figure 8. (a) View of compound 10. Displacement ellipsoids are drawn at the $50 \%$ probability level. Symmetry codes: $\mathrm{i}=2-x,-y, 1-z ; \mathrm{j}=1-x,-y, 1-z ; \mathrm{k}=x-1, y, z ; 1=1-x, 1-y, 1-z ; \mathrm{m}=x+1, y, z$. (b) View of the 2D assembly. (c) Packing with layers viewed edge-on. Uranium coordination polyhedra are yellow and lead atoms are shown as blue spheres. (d) Nodal representation of the 2D network (uranium, yellow; lead, light blue; oxygen, red; dicarboxylate ligand, dark blue; same orientation as in b (top) and view down [100] of one layer edge-on (bottom)). Hydrogen atoms are omitted in all views.

been found in "Pacman" macrocyclic complexes. ${ }^{41}$ This interaction in $\mathbf{1 0}$ is probably rather weak since the difference between the two $\mathrm{U}=\mathrm{O}$ bond lengths [U1-O1 1.775(4) $\AA$, U1-O2 $1.759(4) \AA]$ is not statistically significant. The lead(II) cation is thus heptacoordinate, in an environment of irregular geometry (of the distorted tetragonal base-trigonal base type ${ }^{42}$ ) which can be seen as hemidirected, a possible consequence of the $\mathrm{Pb}^{\mathrm{II}}$ lone pair. ${ }^{43}$ Bonding of the soft nitrogen donors to lead rather than to the harder uranium agrees with HSAB principles, but it is notable that a similar experiment conducted with the $1,2-\mathrm{PDA}^{2-}$ isomer in acetonitrile led to 
complex 2 , in which phen is bound to uranyl and $\mathrm{Pb}^{\mathrm{II}}$ is absent. One of the two 1,3-PDA ${ }^{2-}$ ligands (containing O3 to O6) has its two carboxylate groups pointing on the same side of the aromatic ring, and thus forms $\left[\mathrm{UO}_{2}(1,3-\mathrm{PDA})\right]_{2}$ rings, while the other (O7 to $\left.\mathrm{O} 10\right)$ has one group straddling the aromatic plane. The neutral polymer formed is $2 \mathrm{D}$ and parallel to (001), but it appears to be built from ribbons containing uranium, lead and dicarboxylate nodes parallel to [100], arranged in roof-tile fashion and connected to one another by the oxo links (Figure $8 \mathrm{~d})$. The phen molecules protrude on the two sides of the very thick layers $(\sim 15 \AA)$ and numerous parallel-displaced $\pi$-stacking interactions involving both $1,3-\mathrm{PDA}^{2-}$ and phen aromatic rings, both intra- and interlayer, may be present [centroid...centroid distances 3.453(6)-4.363(6) $\AA$, dihedral angles $\left.0-5.5(4)^{\circ}\right]$, the packing being quite compact (KPI 0.71).

The second uranyl-lead(II) complex, $\left[\left(\mathrm{UO}_{2}\right)_{2} \mathrm{~Pb}_{2}(1,4-\mathrm{PDA})_{3}(\mathrm{HCOO})_{2}(\text { phen })_{2}\right]$ (11), contains an extra formate ligand generated in situ from DMF hydrolysis. The unique uranyl cation is not tris-, but mono-chelated here, three additional carboxylate oxygen donors from three ligands giving a pentagonal bipyramidal uranium environment (Figure 9). Lead(II) is chelated by both the phen and formate ligands (a situation previously encountered in a complex with $1,3,5$-benzenetriacetate ${ }^{36}$ ), and to three oxygen donors from three ligands, its heptacoordinate environment being here also of distorted tetragonal base-trigonal base type (with the formate anion spanning the two bases), and essentially hemidirected. The two inequivalent $1,4-\mathrm{PDA}^{2-}$ ligands (one of them centrosymmetric) are here again in a trans conformation, as in complex 9, and the carboxylate groups adopt the $\mu_{2}-\kappa^{1} O: \kappa^{1} O^{\prime}, \mu_{2}-$ $\kappa^{2} O, O^{\prime}: \kappa^{1} O^{\prime}$ and $\mu_{3}-\kappa^{1} O: \kappa^{1} O: \kappa^{1} O^{\prime}$ coordination modes. The polymer formed is $2 \mathrm{D}$ here also, but its topology is quite different from that in 10. $1 \mathrm{D}$ linear, triple-stranded $\left(\mathrm{UO}_{2}\right)_{2}(1,4-\mathrm{PDA})_{3}{ }^{2-}$ subunits run along [010], with ligands in the central strand doubly coordinated in $\mu_{2}-\kappa^{1} O: \kappa^{1} O^{\prime}$ fashion and forming 8-membered rings with groups of two uranyl ions, and ligands in the outer strands, directed in opposite directions in the two strands, linking uranyl and lead(II) cations. 
These 1D subunits are assembled into a corrugated 2D polymer parallel to (101) by double rows (related by inversion) of $\mathrm{Pb}(\mathrm{HCOO})(\text { phen })^{+}$bridges through coordination of the chain peripheral carboxylate groups. Intralayer parallel-displaced $\pi$-stacking interactions involving 1,4-PDA ${ }^{2-}$ and two phen aromatic rings may be present, as well as interlayer ones involving phen groups only [centroid $\cdots$ centroid distances 3.685(5)-3.913(5) $\AA$, dihedral angles 0 9.7(4) $\left.{ }^{\circ}\right]$. The packing is compact and contains no solvent-accessible space (KPI 0.74).

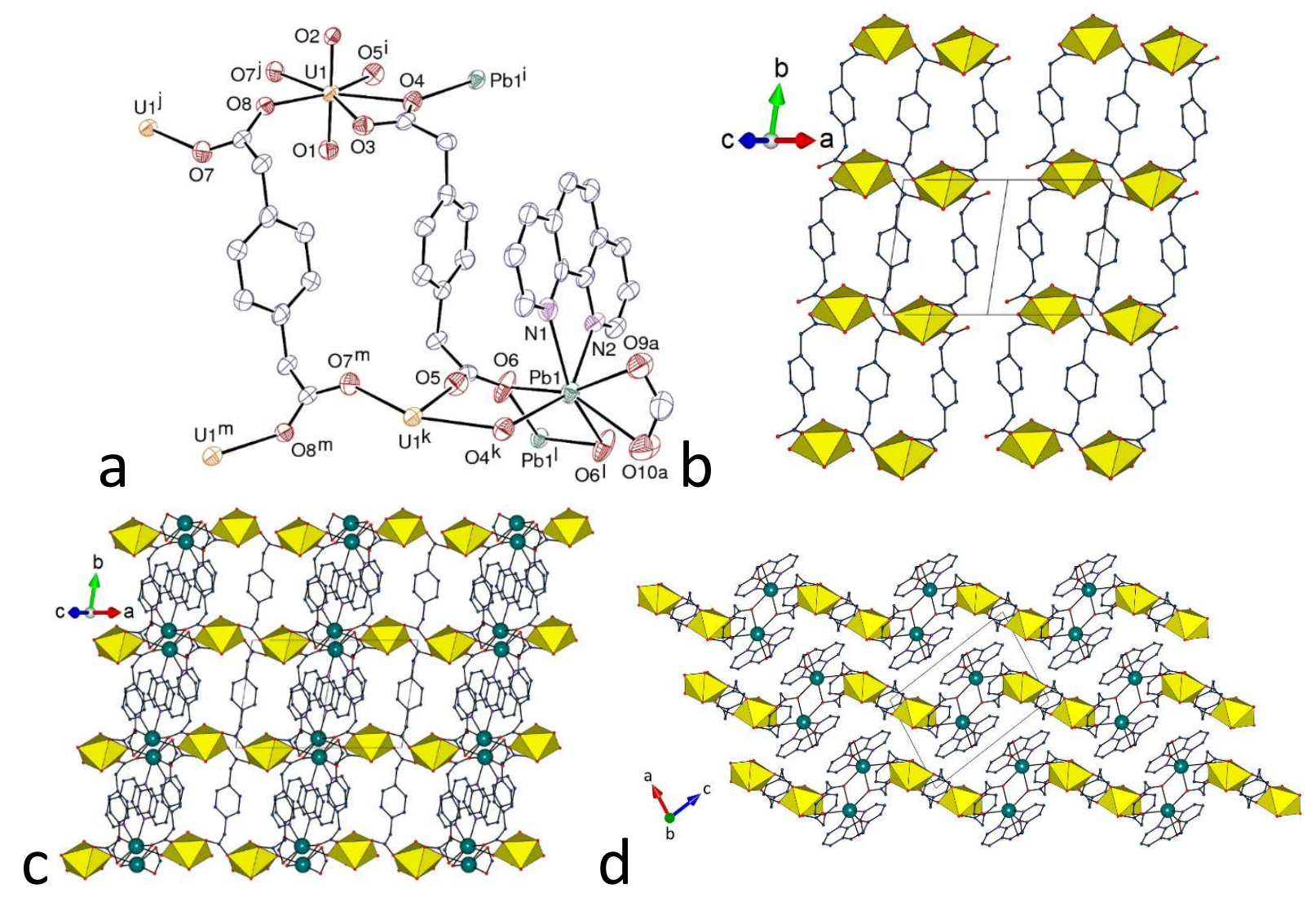

Figure 9. (a) View of compound 11. Displacement ellipsoids are drawn at the $50 \%$ probability level. Symmetry codes: $\mathrm{i}=x, y+1, z ; \mathrm{j}=2-x, 2-y,-z ; \mathrm{k}=x, y-1, z ; 1=1-x,-y, 1-z ; \mathrm{m}=2-x, 1-y,-z$. (b) The triplestranded 1D uranyl-based subunit. (c) View of the 2D assembly. (d) Packing with layers viewed edge-on. Uranium coordination polyhedra are yellow and lead atoms are shown as blue spheres. Only one position of the disordered atoms is represented, and hydrogen atoms are omitted in all views. 
The complex $\left[\mathrm{Zn}(\text { bipy })_{3}\right]\left[\left(\mathrm{UO}_{2}\right)_{2}(1,2-\mathrm{PDA})(1,4-\mathrm{PDA})_{2}\right] \cdot \mathrm{H}_{2} \mathrm{O}(\mathbf{1 2})$ is an exception in the present series since it contains a mixture of two ligand isomers (other complexes with such mixed ligands, but devoid of metallic counterion, will be reported in due time). The aim here was to benefit from both the potentially convergent nature of $1,2-\mathrm{PDA}^{2-}$, as found in 6 , and the divergent one of 1,4-PDA ${ }^{2-}$, as found in 9 and 11, but the large flexibility of these ligands resulted in these expectations being somewhat thwarted, although the periodicity increase is nevertheless attained. The two inequivalent uranyl cations are both chelated by three carboxylate groups, and the metallic counterion is once more separate (Figure 10). The unique

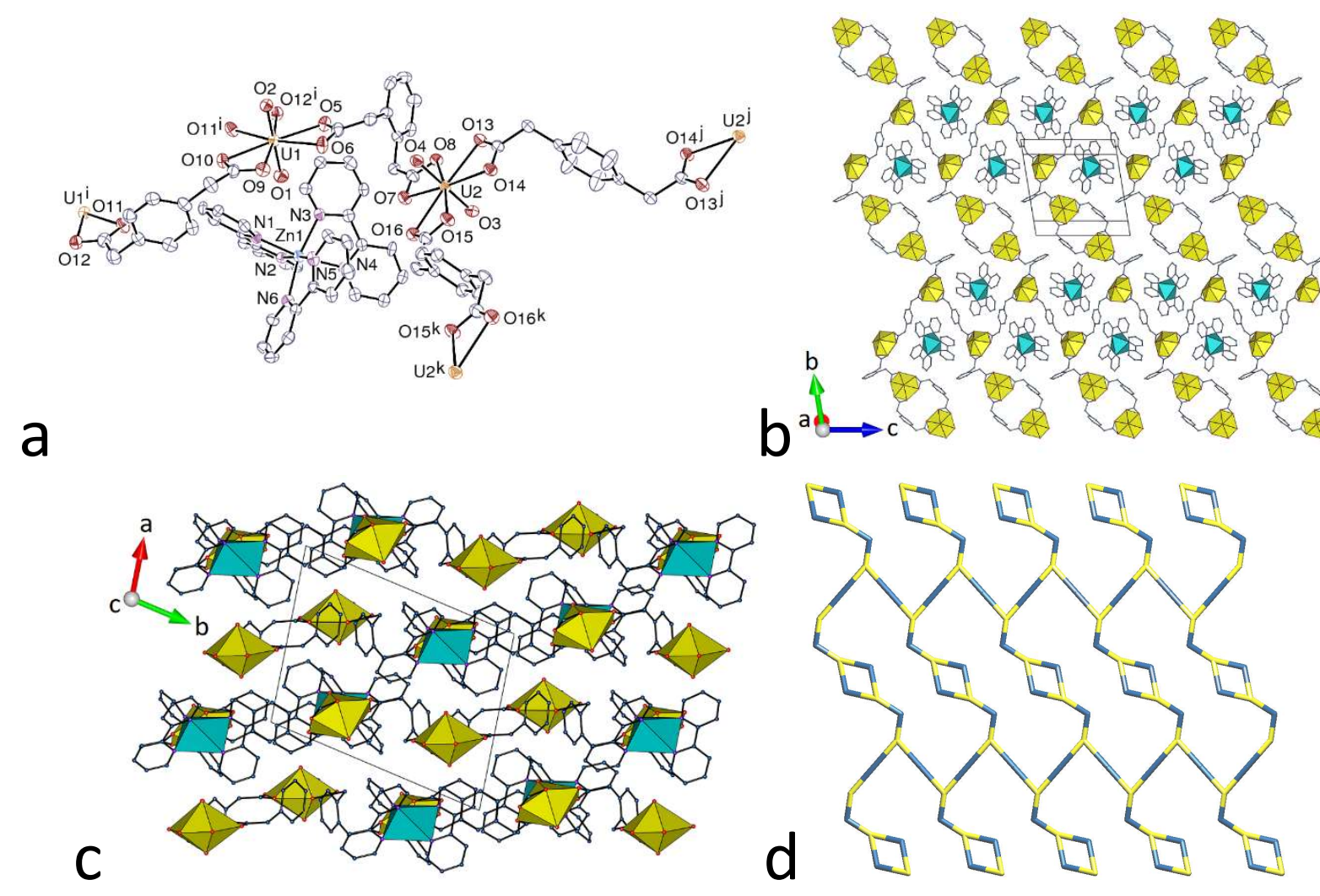

Figure 10. (a) View of compound 12. Displacement ellipsoids are drawn at the $40 \%$ probability level. Symmetry codes: $\mathrm{i}=1-x, 2-y, 1-z ; \mathrm{j}=-x,-y, 2-z ; \mathrm{k}=-x,-y, 1-z$. (b) View of the 2D assembly and associated counterions. (c) Packing with layers viewed edge-on. Uranium coordination polyhedra are yellow and those of zinc blue. (d) Nodal representation of the 2D network (uranium nodes, yellow; dicarboxylate ligand links, dark blue; same orientation as in b). Solvent molecules and hydrogen atoms are omitted in all views. 
$1,2-\mathrm{PDA}^{2-}$ ligand adopts the same pseudo- $C_{2}$ conformation as in $\mathbf{1}$, and is thus divergent. There are three independent $1,4-\mathrm{PDA}^{2-}$ ligands, two of them centrosymmetric. The latter adopt the divergent, trans conformation previously found, but the former has its two carboxylate groups pointing on the same side of the aromatic ring, and it can thus be considered as convergent. As a result, this latter, convergent ligand forms $\left[\mathrm{UO}_{2}(1,4-\mathrm{PDA})\right]_{2}$ rings (containing $\mathrm{U} 1$ and its image by inversion), similar to those found with $1,3-\mathrm{PDA}^{2-}$ in $\mathbf{1 0}$, both being much flatter than the saddle-shaped ones in $\mathbf{6}$. These rings are arranged in rows running along [001], which are linked to one another by zigzag chains parallel to the same direction, containing U2 and its images by symmetry and the trans $1,4-\mathrm{PDA}^{2-}$ ligands, the bridging of the two subunits being through the $1,2-\mathrm{PDA}^{2-}$ ligands. The polymer thus formed is $2 \mathrm{D}$ and extends parallel to $(2 \overline{1} 0)$ with gentle undulations only. From a topological viewpoint, the uranyl ions are 3-connected nodes and the ligands are simple links. Elongated rings, of $\sim 35 \AA$ in length, containing six uranyl cations from the zigzag chains and two $\left[\mathrm{UO}_{2}(1,4-\mathrm{PDA})\right]_{2}$ rings are formed, which are derived from the simple honeycomb (hcb) network by replacement of two links by two dinuclear rings and their attachment. The lateral parts of these elongated rings, defined by the zigzag chains, are occupied by the $\left[\mathrm{Zn}(\text { bipy })_{3}\right]^{2+}$ counterions. A similar $2 \mathrm{D}$ network was found in the complex $\left[\mathrm{Ni}(\text { phen })_{3}\right]\left[\left(\mathrm{UO}_{2}\right)_{2}(1,4-\mathrm{PDA})_{3}\right] \cdot \mathrm{H}_{2} \mathrm{O},{ }^{16}$ with $1,4-\mathrm{PDA}^{2-}$ ligands only; the sheets are slightly more corrugated in this case and the larger size of the counterion prevents its inclusion within the rings, its location being between sheets. In complex 12, intralayer paralleldisplaced $\pi$-stacking interactions involving the 1,4-PDA ${ }^{2-}$ ligands of the zigzag chains and the aromatic rings of the bipy molecules may be present, and also interlayer interactions involving

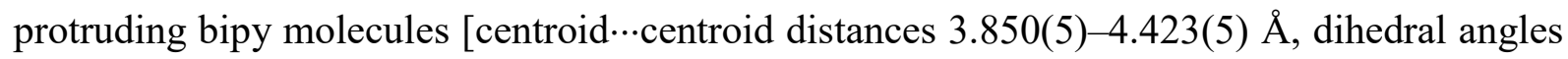
$\left.0-15.3(4)^{\circ}\right]$. Here also, the packing of the layers is quite compact (KPI 0.69).

The last two compounds contain the 1,3-PDA ${ }^{2-}$ ligand and $3 \mathrm{~d}$ metal cations complexed by azamacrocycles as counterions. In the complex $\left[\mathrm{Cu}\left(R, S-\mathrm{Me}_{6}\right.\right.$ cyclam $\left.)\right]\left[\mathrm{UO}_{2}(1,3-\right.$ 
PDA) $\left.\left(\mathrm{NO}_{3}\right)\right]_{2}(\mathbf{1 3})$, the unique uranyl cation is chelated by two carboxylate groups and one nitrate anion (Figure 11). The 1,3-PDA ${ }^{2-}$ ligand is in the chiral trans conformation and the $1 \mathrm{D}$

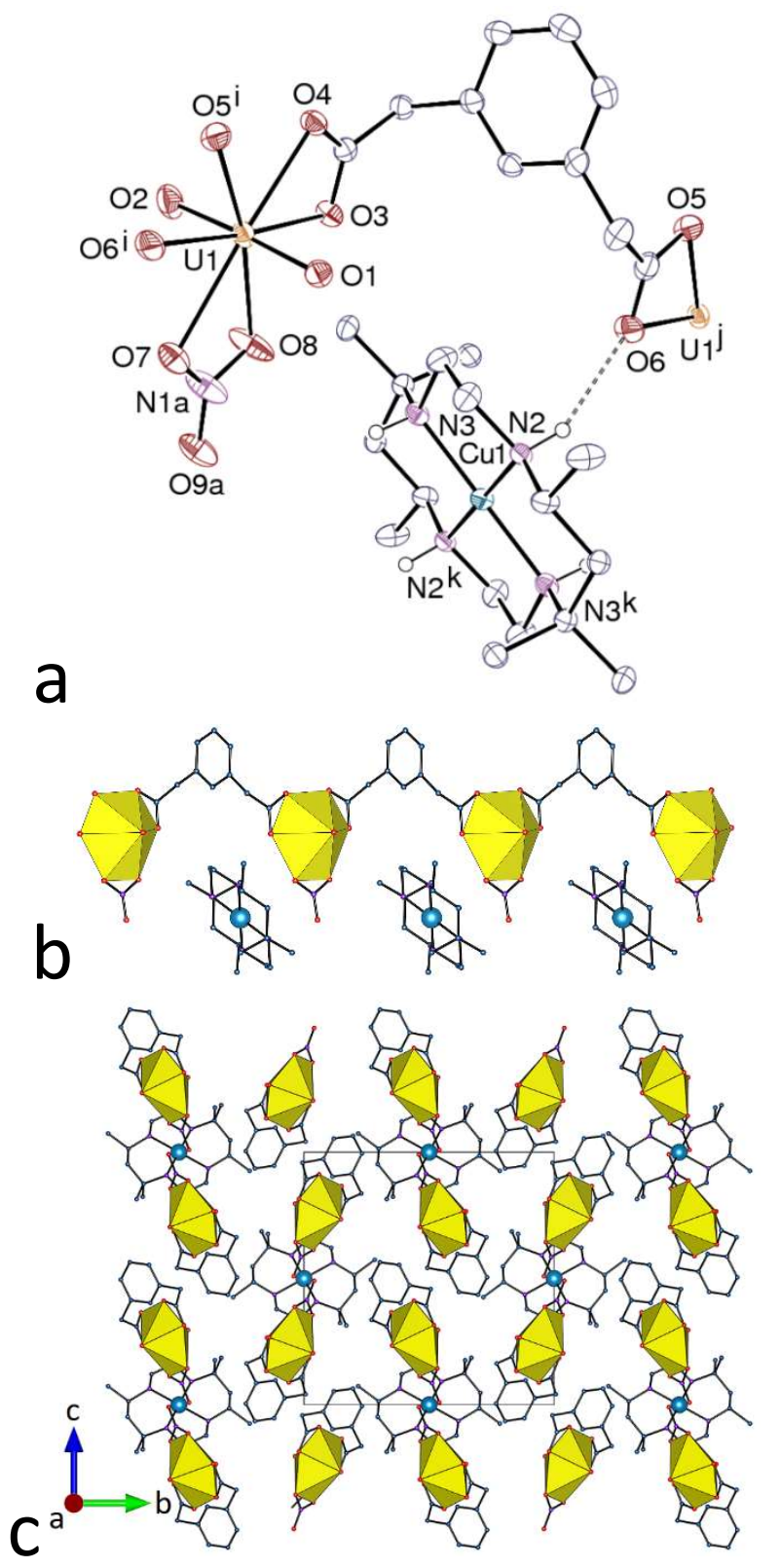

Figure 11. (a) View of compound 13. Displacement ellipsoids are drawn at the $40 \%$ probability level. Carbonbound hydrogen atoms are omitted and the hydrogen bond is shown as a dashed line. Symmetry codes: $\mathrm{i}=x-1$, $y, z ; \mathrm{j}=x+1, y, z ; \mathrm{k}=1-x, 1-y,-z$. (b) View of the 1D polymer and associated counterions. (c) Packing with chains viewed end-on. Uranium coordination polyhedra are yellow and copper atoms are shown as blue spheres. Only one position of the disordered atoms is represented in all views. 
coordination polymer formed, parallel to [100], is analogous to those found with $1,2-\mathrm{PDA}^{2-}$ in 7 and $\mathbf{8}$. The $\mathrm{Cu}^{\mathrm{II}}$ cation, located on an inversion centre, is bound to the four nitrogen atoms of the macrocycle $[\mathrm{Cu}-\mathrm{N} 2.029(3)$ and 2.035(3) $\AA]$, and the lack of axial coordination (even though such coordination is known in related compounds ${ }^{44}$ ) makes it ineffective in periodicity increase. The NH groups of the macrocycle are however involved in hydrogen bonding with one carboxylate (O6) and two nitrate (O7 and O9, the latter disordered) oxygen atoms [N… 3.084(4)-3.296(10) $\left.\AA, \mathrm{N}-\mathrm{H} \cdots \mathrm{O} 131-153^{\circ}\right]$, and the $\mathrm{HS}$ of the $\mathrm{Cu}^{\mathrm{II}}$ complex only provides evidence for a strong $\mathrm{CH} \cdots \mathrm{O}$ interaction involving the uncomplexed nitrate atom $\mathrm{O} 9$, all these interactions possibly favouring incorporation of nitrate in the product. These hydrogen bonds result in the dimerization of chains adjacent along [001]. The packing involves no $\pi$-stacking interaction and does not contain significant free space (KPI 0.72).

Replacement of $\left[\mathrm{Cu}\left(R, S-\mathrm{Me}_{6} \mathrm{cyclam}\right)\right]^{2+}$ by $[\mathrm{Ni}(\text { cyclam })]^{2+}$ has a marked effect on the structure, the trans chiral conformation of the 1,3-PDA ${ }^{2-}$ ligand being almost the only feature of the structure of complex 13 retained in that of the complex $[\mathrm{Ni}($ cyclam $)]\left[\left(\mathrm{UO}_{2}\right)_{2}(1,3-\mathrm{PDA})_{3}\right]$ (14). Although this complex has a 1:3 uranyl/carboxylate ratio, the two inequivalent uranium centres have a pentagonal bipyramidal coordination geometry (Figure 12). Both uranyl ions are chelated by one carboxylate group and are bound to three additional carboxylate donors from three more ligands, as found in complex 11. As in this latter complex and notwithstanding the difference in ligand isomeric form, a triply stranded 1D uranyl-only coordination polymeric subunit is formed, that runs parallel to [100]. Ligands in the central strand are doubly coordinated in a $\mu_{2}-\kappa^{1} O: \kappa^{1} O^{\prime}$ bridging manner, as in $\mathbf{1 1}$, and ligands in the outer strands have chirality opposite to that of the ligands in the central strand. The $\mathrm{Ni}^{\mathrm{II}}$ cation is bound to the four macrocyclic nitrogen atoms $[\mathrm{Ni}-\mathrm{N} 2.056(16)-2.085(18) \AA]$, but, in contrast to the case of complex $\mathbf{1 3}$, it is also axially bound to two carboxylate oxygen atoms [Ni-O 2.120(9) and 2.128(9) $\AA$ ], which gives a slightly axially elongated octahedral environment. Although in 

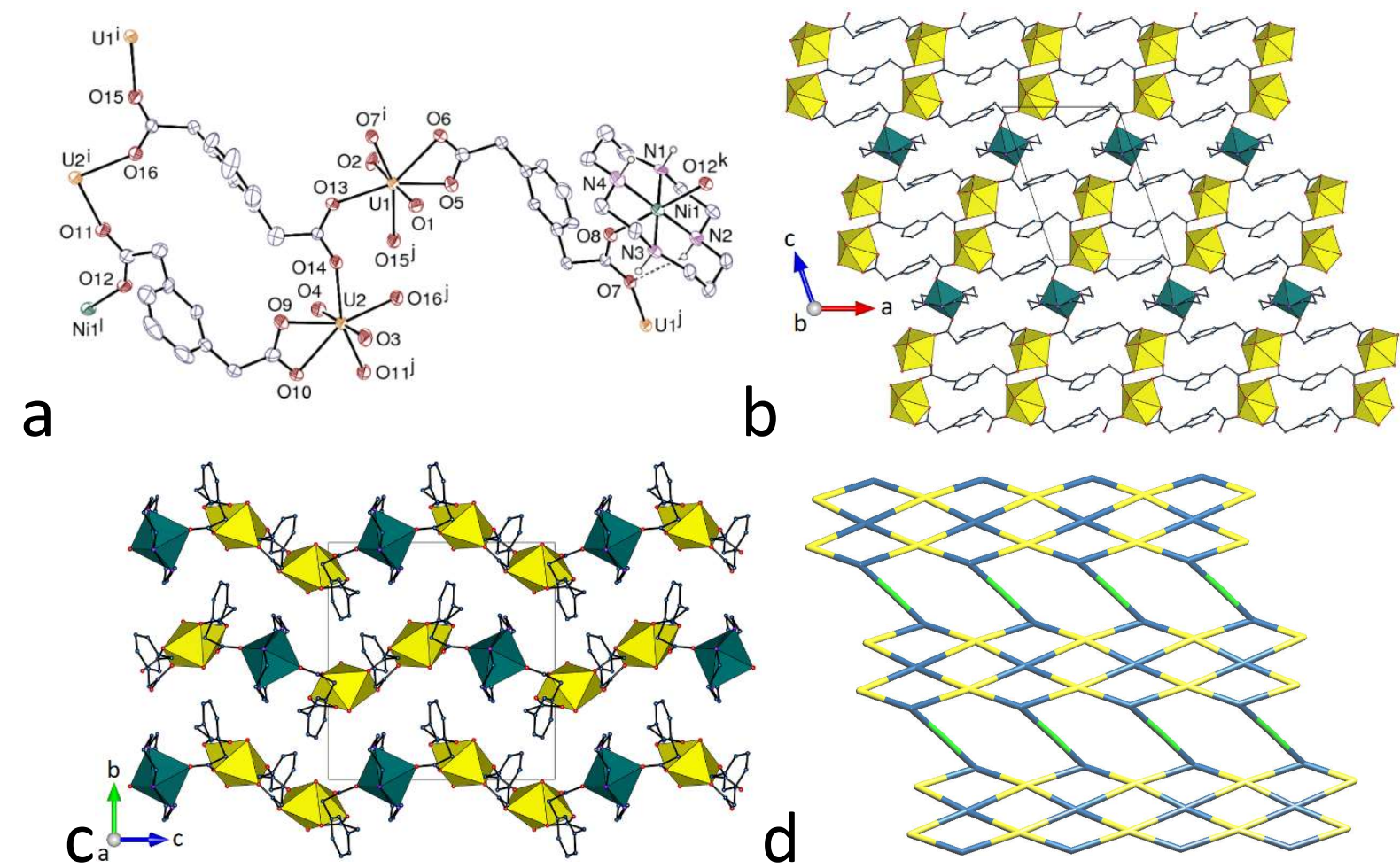

Figure 12. (a) View of compound 14. Displacement ellipsoids are drawn at the $30 \%$ probability level. Carbonbound hydrogen atoms are omitted and the hydrogen bond is shown as a dashed line. Symmetry codes: $\mathrm{i}=x-1$, $y, z ; \mathrm{j}=x+1, y, z ; \mathrm{k}=x+1, y, z-1 ; 1=x-1, y, z+1$. (b) View of the 2D assembly. (c) Packing with layers viewed edge-on. Uranium coordination polyhedra are yellow and those of nickel green. (d) Nodal representation of the 2D network (uranium nodes, yellow; nickel links, green; dicarboxylate ligand nodes, dark blue; same orientation as in b).

general axial interactions of carboxylate groups with complexes such as $[\mathrm{Ni}(\mathrm{cyclam})]^{2+}$ appear to result from a combination of direct coordination and $\mathrm{NH} \cdots \mathrm{O}$ bonding, ${ }^{17}$ here the $\mathrm{Ni}-\mathrm{O}$ distances are short and coordination appears to be dominant, even though the HS shows it to be assisted by hydrogen bonding to the adjacent carboxylate groups. Ligands in the outer strands thus link uranyl and nickel(II) centres unsymmetrically through $\kappa^{2} O, O^{\prime}$ and $\mu_{2-} \kappa^{1} O: \kappa^{1} O^{\prime}$ coordination, with the ligand directions being opposite in the two strands, and four 20membered rings are thus fused onto every 8 -membered one. While the presence of formate ions in 11 results in the presence of double rows of $\mathrm{Pb}(\mathrm{HCOO})(\text { phen })^{+}$bridges uniting the uranyl- 
containing $1 \mathrm{D}$ subunits, single rows of $[\mathrm{Ni}(\mathrm{cyclam})]^{2+}$ cations are present here, and the gently undulated 2D polymer is parallel to (010). Hydrogen bonding of $\mathrm{NH}$ groups to carboxylate

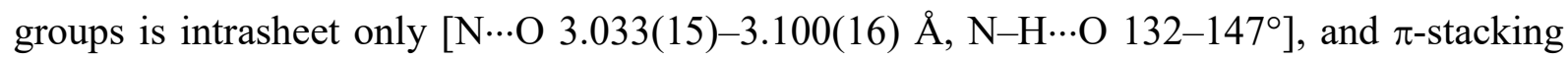
interactions are absent. The KPI of 0.66 only indicates that small voids may be occupied by disordered water molecules.

All the uranyl ion complexes obtained so far with 1,2-, 1,3- and 1,4-PDA ${ }^{2-}$ ligands are summarized in Table 3, which gives the ligand coordination modes, the periodicity and details

Table 3. Uranyl Ion Complexes with 1,2-, 1,3-, and 1,4-PDA ${ }^{2-}$

\begin{tabular}{|c|c|c|c|c|}
\hline compound & ligand coordination mode & periodicity & geometry/topology & ref \\
\hline \multicolumn{5}{|l|}{$1,2-\mathrm{PDA}^{2-}$} \\
\hline$\left[\mathrm{UO}_{2}(1,2-\mathrm{PDA})(\right.$ bipy $\left.)\right] \cdot \mathrm{CH}_{3} \mathrm{CN}$ & $\kappa^{2} O, O^{\prime}$ & 1 & simple chain & this work \\
\hline$\left[\mathrm{UO}_{2}(1,2-\mathrm{PDA})(\mathrm{phen})\right]$ & $\kappa^{2} O, O^{\prime}$ & 1 & zigzag chain & this work \\
\hline$\left[\mathrm{UO}_{2}(1,2-\mathrm{PDA})_{2} \mathrm{Zn}(\text { phen })_{2}\right] \cdot 2 \mathrm{H}_{2} \mathrm{O}$ & $\kappa^{2} O, O^{\prime}$ & 1 & simple chain & 16 \\
\hline$\left[\mathrm{Cu}(\text { bipy })_{2}\left(\mathrm{NO}_{3}\right)\right]\left[\mathrm{UO}_{2}(1,2-\mathrm{PDA})\left(\mathrm{NO}_{3}\right)\right]$ & $\kappa^{2} O, O^{\prime}$ & 1 & simple chain & this work \\
\hline$\left[\mathrm{Ag}(\text { bipy })_{2}\right]\left[\mathrm{UO}_{2}(1,2-\mathrm{PDA})\left(\mathrm{NO}_{3}\right)\right]$ & $\kappa^{2} O, O^{\prime}$ & 1 & simple chain & this work \\
\hline$\left[\mathrm{H}_{2}-2.2 \cdot 2\right]\left[\left(\mathrm{UO}_{2}\right)_{2}(1,2-\mathrm{PDA})_{3}\right] \cdot \mathrm{CH}_{3} \mathrm{CN}$ & $\kappa^{2} O, O^{\prime}$ & 1 & ladderlike chain & this work \\
\hline$\left[\mathrm{Zn}(\text { phen })_{3}\right]\left[\left(\mathrm{UO}_{2}\right)_{2}(1,2-\mathrm{PDA})_{3}\right] \cdot 7 \mathrm{H}_{2} \mathrm{O}$ & $\kappa^{2} O, O^{\prime}$ & 1 & ladderlike chain & 16 \\
\hline $\begin{array}{l}{\left[\mathrm{NH}_{4}\right]_{6}\left[\mathrm{Ni}_{(}\left(\mathrm{H}_{2} \mathrm{O}\right)_{6}\right]_{2}\left[\left(\mathrm{UO}_{2}\right)_{4}(1,2-\mathrm{PDA})_{6}\right]_{2}\left[\left(\mathrm{UO}_{2}\right)_{4}(1,2-\right.} \\
\left.\mathrm{PDA})_{5}\left(\mathrm{H}_{2} \mathrm{O}\right)_{4}\right]\end{array}$ & $\kappa^{2} O, O^{\prime}$ & $0+1$ & tetranuclear complex + helical chain & this work \\
\hline \multicolumn{5}{|l|}{ 1,3-PDA ${ }^{2-}$} \\
\hline$\left[\mathrm{UO}_{2}(1,3-\mathrm{PDA})(\right.$ bipy $\left.)\right]$ & $\kappa^{2} O, O^{\prime}$ & 1 & simple chain & this work \\
\hline$\left[\mathrm{UO}_{2}(1,3-\mathrm{PDA})(\mathrm{phen})\right]$ & $\kappa^{2} O, O^{\prime}$ & 1 & simple chain & this work \\
\hline$\left[\mathrm{Zn}(\mathrm{phen})_{3}\right]\left[\left(\mathrm{UO}_{2}\right)_{2}(1,3-\mathrm{PDA})_{3}\right]$ & $\kappa^{2} O, O^{\prime}$ & 2 & heb & 16 \\
\hline$\left[\mathrm{Zn}(\text { bipy })_{3}\right]\left[\left(\mathrm{UO}_{2}\right)_{2}(1,3-\mathrm{PDA})_{3}\right]$ & $\kappa^{2} O, O^{\prime}$ & 1 & tubelike chain & 16 \\
\hline$\left[\mathrm{UO}_{2} \mathrm{~Pb}(1,3-\mathrm{PDA})_{2}(\mathrm{phen})\right]$ & $\kappa^{2} O, O^{\prime} / \mu_{2}-\kappa^{2} O, O^{\prime}: \kappa^{1} O^{\prime}$ & 2 & oxo-linked ribbons & this work \\
\hline$\left[\mathrm{Cu}\left(R, S-\mathrm{Me}_{6}\right.\right.$ cyclam $\left.)\right]\left[\mathrm{UO}_{2}(1,3-\mathrm{PDA})\left(\mathrm{NO}_{3}\right)\right]_{2}$ & $\kappa^{2} O, O^{\prime}$ & 1 & simple chain & this work \\
\hline$[\mathrm{Ni}($ cyclam $)]\left[\left(\mathrm{UO}_{2}\right)_{2}(1,3-\mathrm{PDA})_{3}\right]$ & $\kappa^{2} O, O^{\prime} / \mu_{2}-\kappa^{1} O: \kappa^{1} O^{\prime}$ & 2 & Ni-linked triple-stranded ribbons & this work \\
\hline \multicolumn{5}{|l|}{ 1,4-PDA ${ }^{2-}$} \\
\hline$\left[\mathrm{Ag}(\text { bipy })_{2}\right]\left[\mathrm{UO}_{2}(1,4-\mathrm{PDA})\left(\mathrm{NO}_{3}\right)\right]$ & $\kappa^{2} O, O^{\prime}$ & 1 & zigzag chain & this work \\
\hline$\left[\mathrm{UO}_{2}(1,4-\mathrm{PDA})_{2} \mathrm{Mn}(\text { bipy })_{2}\right] \cdot \mathrm{H}_{2} \mathrm{O}$ & $\kappa^{2} O, O^{\prime} / \mu_{2}-\kappa^{1} O: \kappa^{1} O^{\prime}$ & 1 & ring-incorporating chain & 16 \\
\hline$\left[\mathrm{Ni}(\text { phen })_{3}\right]\left[\left(\mathrm{UO}_{2}\right)_{2}(1,4-\mathrm{PDA})_{3}\right] \cdot \mathrm{H}_{2} \mathrm{O}$ & $\kappa^{2} O, O^{\prime}$ & 2 & ring-incorporating hcb & 16 \\
\hline$\left[\mathrm{Zn}(\text { bipy })_{3}\right]\left[\left(\mathrm{UO}_{2}\right)_{2}(1,2-\mathrm{PDA})(1,4-\mathrm{PDA})_{2}\right] \cdot \mathrm{H}_{2} \mathrm{O}$ & $\kappa^{2} O, O^{\prime}$ & 2 & ring-incorporating hcb & this work \\
\hline$\left[\mathrm{Cu}(\text { bipy })_{2}\right]\left[\mathrm{H}_{2} \mathrm{NMe}_{2}\right]\left[\left(\mathrm{UO}_{2}\right)_{2}(1,4-\mathrm{PDA})_{3}\right]$ & $\kappa^{2} O, O^{\prime}$ & 2 & 2-fold interpenetrated $\mathbf{h c b}$ & 16 \\
\hline$\left[\mathrm{M}(\text { bipy })_{3}\right]\left[\left(\mathrm{UO}_{2}\right)_{2}(1,4-\mathrm{PDA})_{3}\right](\mathrm{M}=\mathrm{Co}, \mathrm{Ni}, \mathrm{Ru})$ & $\kappa^{2} O, O^{\prime}$ & 1 & tubelike chain & 16 \\
\hline$\left[\left(\mathrm{UO}_{2}\right)_{2} \mathrm{~Pb}_{2}(1,4-\mathrm{PDA})_{3}(\mathrm{HCOO})_{2}(\text { phen })_{2}\right]$ & $\begin{array}{l}\mu_{2}-\kappa^{1} O: \kappa^{1} O^{\prime} / \mu_{2}-\kappa^{2} O, O^{\prime}: \kappa^{1} O^{\prime} / \mu_{3}- \\
\kappa^{1} O: \kappa^{1} O: \kappa^{1} O^{\prime}\end{array}$ & 2 & $\mathrm{~Pb}$-linked triple-stranded ribbons & this work \\
\hline
\end{tabular}


on the geometry and/or topology of the species formed. It appears quite obvious that all three ligands have a marked preference for the $\kappa^{2} O, O^{\prime}$ (chelating) coordination mode, with only four cases (none with 1,2-PDA ${ }^{2-}$ ) in which this mode is associated to diverse bridging interactions. Another conspicuous fact, partly related to the preference in coordination mode, is that the coordination polymers formed are most often 1D (17 occurrences), with only 7 examples of 2D networks, here also none of them with 1,2-PDA ${ }^{2-}$. It is equally notable that, in two of the $2 \mathrm{D}$ arrangements (complexes $\mathbf{1 1}$ and 14), triple-stranded 1D uranyl-only subunits are found. Concerning the other 2D assemblies, two of the previously reported complexes, $\left[\mathrm{Zn}(\text { phen })_{3}\right]\left[\left(\mathrm{UO}_{2}\right)_{2}(1,3-\mathrm{PDA})_{3}\right]$ and $\left[\mathrm{Cu}(\text { bipy })_{2}\right]\left[\mathrm{H}_{2} \mathrm{NMe}_{2}\right]\left[\left(\mathrm{UO}_{2}\right)_{2}(1,4-\mathrm{PDA})_{3}\right]$, possess the hcb topology, with network interpenetration in the latter case, ${ }^{16}$ while $\left[\mathrm{Ni}(\mathrm{phen})_{3}\right]\left[\left(\mathrm{UO}_{2}\right)_{2}(1,4-\right.$ $\left.\mathrm{PDA})_{3}\right] \cdot \mathrm{H}_{2} \mathrm{O}$ and complex 12 display larger, decanuclear rings derived from the hexagonal ones by replacement of two links by two dinuclear rings and their attachment (a topology previously found in a uranyl ion complex with 1,8-octanedicarboxylate and $\left[\mathrm{Ni}(\text { bipy })_{3}\right]^{2+}$ counterions $\left.{ }^{45}\right)$. Complex 12 is a rare example of a uranyl compound with mixed carboxylate ligands (the common cases in which one is formate or oxalate being disregarded), probably attainable due to the closely matched complexing power of both components.

While all these results have shown that the three phenylenediacetate isomers may be found in conformations in which the two carboxylate groups are oriented either divergently or convergently with respect to the aromatic ring (as well as conformations which are intermediate), and although convergent geometries are essential to the formation of tubelike species, ${ }^{16}$ divergency does seem to be favoured overall. This is perhaps to be expected given that the preferred $\kappa^{2}-O, O^{\prime}$ binding mode of the carboxylate groups must produce extremely large attachments on the aromatic ring. It is a factor which militates against the formation of discrete, closed polynuclear species such as those observed with various aliphatic dicarboxylates, $5,9,14,15,46,47$ although it would not seem that in their attainable convergent 
conformations the phenylenediacetates fail to meet the geometric requirements for formation of small, polynuclear closed species. ${ }^{47,48}$ Given that where such species are known, their formation is very dependent on the choice of counterion, the present results indicate that the phenylenediacetates are more resistant to these influences, since a cation such as, for example, $\mathrm{NH}_{4}{ }^{+}$, which has been associated with closed-species formation in several other systems, ${ }^{14,15,37,47}$ does not have that influence here. However, the inclusion of $\mathrm{NH}_{4}{ }^{+}$into the clefts defined by the saddle-shaped dimers in $\mathbf{6}$ is possibly indicative of structure-directing effects analogous to those leading to the formation of closed species. The possibility that the aromatic ring interactions of the phenylenediacetates may have a significant influence on the solid state structures, thus explaining their differences from aliphatic systems, appears to be denied by the fact that any stacking arrays are only prominent in the species where bipy or phen ligands are also present. The Hirshfeld surfaces do, however, provide evidence of peripheral aromatic- $\mathrm{CH} \cdots \mathrm{O}$ interactions which, in systems where obviously a large number of different weak interactions are operative, may be sufficient to tip the balance towards open polymers rather than closed oligomers, the outcome being however quite unpredictable.

Luminescence properties. Emission spectra under excitation at $420 \mathrm{~nm}$ were recorded for complexes $\mathbf{1}, \mathbf{2}, \mathbf{4}, \mathbf{7}-\mathbf{1 0}$ and $\mathbf{1 2 - 1 4}$ in the solid state, a sufficient quantity of pure sample being unavailable in the other cases. Complexes $\mathbf{1 3}$ and $\mathbf{1 4}$ are nearly non-emissive, probably due to the $\mathrm{d}$ block metal cation present $\left(\mathrm{Cu}^{\mathrm{II}}\right.$ and $\mathrm{Ni}^{\mathrm{II}}$, respectively) providing nonradiative relaxation pathways. ${ }^{49-54}$ In all other cases, the spectra display the usual fine structure associated with the vibronic progression corresponding to the $S_{11} \rightarrow S_{00}$ and $S_{10} \rightarrow S_{0 v}(v=0$ 4) electronic transitions ${ }^{55}$ (Figures 13 and 14). In all these cases in which well-resolved spectra are obtained, the uranium centres are in tris-chelated hexagonal bipyramidal environments. The positions of the four most intense maxima vary within a $\sim 8 \mathrm{~nm}$ range, the most blueshifted 


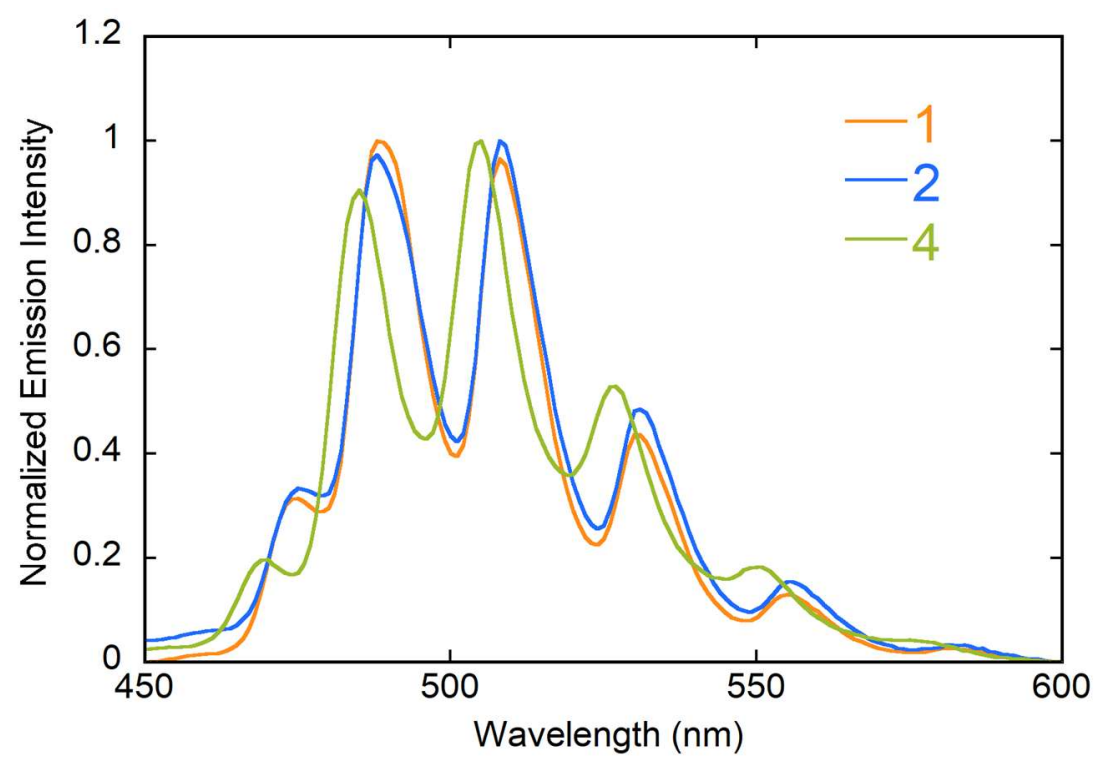

Figure 13. Emission spectra of the homometallic compounds 1, 2 and $\mathbf{4}$ in the solid state at room temperature, under excitation at a wavelength of $420 \mathrm{~nm}$.

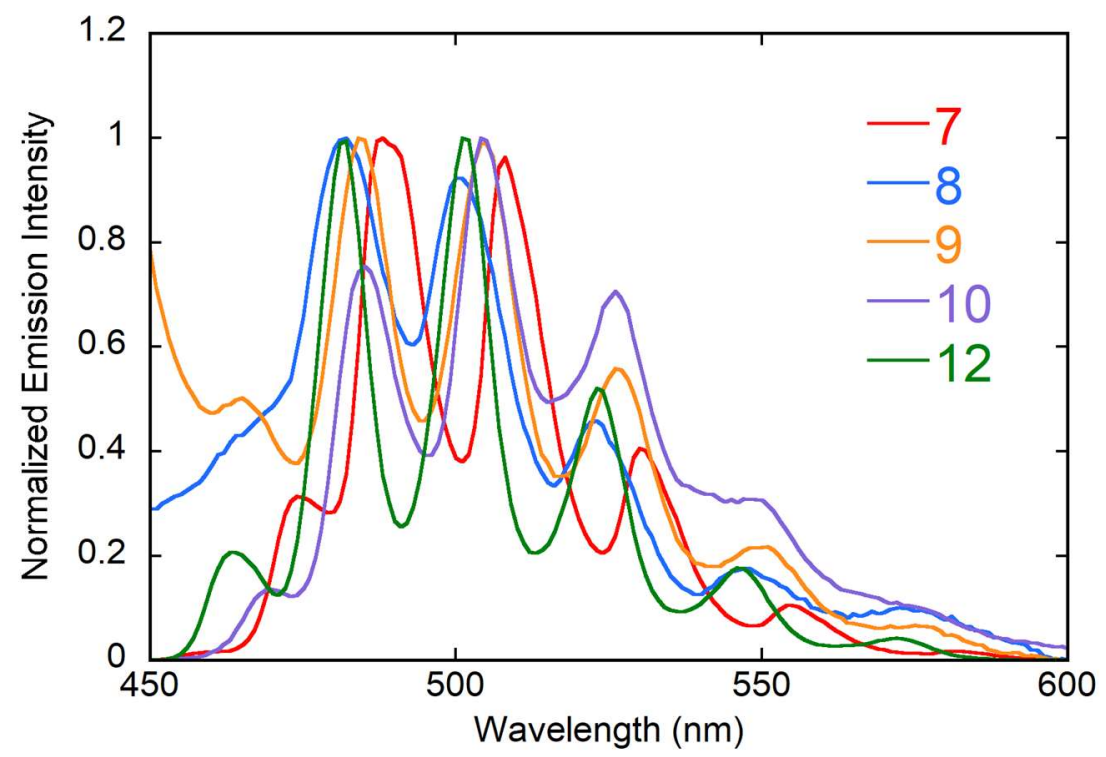

Figure 14. Emission spectra of the heterometallic compounds $\mathbf{7 - 1 0}$ and $\mathbf{1 2}$ in the solid state at room temperature, under excitation at a wavelength of $420 \mathrm{~nm}$.

being those of complexes 8 and $\mathbf{1 2}(482,500,523$ and $547 \mathrm{~nm} \pm 1 \mathrm{~nm})$, and the most redshifted being those of 1,2 and $7(488,508,531$ and $555 \mathrm{~nm})$. All these values are within the range generally observed for hexagonal bipyramidal uranyl carboxylate complexes with $\mathrm{O}_{6}$ or $\mathrm{O}_{4} \mathrm{~N}_{2}$ equatorial environments, the latter environment corresponding to values in the upper part of the 
range, ${ }^{39,45}$ as for complexes $\mathbf{1}$ and $\mathbf{2}$. Larger redshifts are generally observed for complexes with uranyl ions in pentagonal bipyramidal environments. ${ }^{39}$ Solid-state photoluminescence quantum yields (PLQYs) have been measured for complexes 2, 4, 7-10 and 12, and they are all very weak, at about $1 \%$.

\section{CONCLUSIONS}

The three positional isomers of phenylenediacetate have been used to synthesize 14 uranyl ion complexes, in which the uranyl cation is most often tris-chelated. Five compounds are homometallic and include either additional chelating $N$-donor ligands (bipy, phen) or protonated [2.2.2]cryptand as counterion, and the others are heterometallic, with additional metal cations $\left(\mathrm{Ni}^{2+}, \mathrm{Cu}^{2+}, \mathrm{Zn}^{2+} \mathrm{Ag}^{+}, \mathrm{Pb}^{2+}\right)$ generally bound to $\mathrm{N}$-donor ligands (bipy, phen, cyclam, $R, S$-Me ( $_{6}$ cyclam). Together with those for the 10 complexes with the same phenylenediacetate ligands previously reported, which include $\left[\mathrm{M}(\mathrm{L})_{n}\right]^{q+}$ cations $\left(\mathrm{M}=\mathrm{Mn}^{2+}\right.$, $\mathrm{Co}^{2+}, \mathrm{Ni}^{2+}, \mathrm{Cu}^{+}, \mathrm{Zn}^{2+}$ or $\mathrm{Ru}^{2+}, \mathrm{L}=$ bipy or phen, $n=2$ or 3 , and $q=1$ or 2 ), these results provide an extended overview of the uranyl-complexing properties of these dicarboxylates. Although these are ditopic ligands which can adopt both convergent and divergent geometries, it is notable that none of the experimental conditions used provided a discrete polynuclear closed species or a polymeric triperiodic framework, although convergence plays an essential part in the formation of monoperiodic tubelike assemblies. ${ }^{16}$ All three ligands appear to have a strong propensity, particularly marked for $1,2-\mathrm{PDA}^{2-}$, to bind to uranyl ions in the bis-chelating mode and to form 1D polymers, a tendency which can only be partially overcome through use of bulky counterions as structure-directing species, or additional, complexed metal cations.

\section{ASSOCIATED CONTENT}

\section{Accession Codes}


CCDC 1944962-1944975 contain the supplementary crystallographic data for this paper. These data can be obtained free of charge via www.ccdc.cam.ac.uk/data_request/cif, or by emailing data_request@ccdc.cam.ac.uk, or by contacting The Cambridge Crystallographic Data Centre, 12 Union Road, Cambridge CB2 1EZ, UK; fax: +44 1223336033.

\section{AUTHOR INFORMATION}

\section{Corresponding Authors}

*E-mail: pierre.thuery@cea.fr. (P.T.)

*E-mail: harrowfield@unistra.fr. (J.H.)

\section{ORCID}

Pierre Thuéry: 0000-0003-1683-570X

Youssef Atoini: 0000-0003-4851-3713

Jack Harrowfield: 0000-0003-4005-740X

\section{Notes}

The authors declare no competing financial interest.

\section{REFERENCES}

1. Wang, K. X.; Chen, J. S. Extended Structures and Physicochemical Properties of UranylOrganic Compounds. Acc. Chem. Res. 2011, 44, 531-540.

2. Andrews, M. B.; Cahill, C. L. Uranyl Bearing Hybrid Materials: Synthesis, Speciation, and Solid-State Structures. Chem. Rev. 2013, 113, 1121-1136. 
3. Loiseau, T.; Mihalcea, I.; Henry, N.; Volkringer, C. The Crystal Chemistry of Uranium Carboxylates. Coord. Chem. Rev. 2014, 266-267, 69-109.

4. Su, J.; Chen, J. S. MOFs of Uranium and the Actinides. Struct. Bond. 2015, 163, 265-296.

5. Thuéry, P.; Harrowfield, J. Recent Advances in Structural Studies of Heterometallic UranylContaining Coordination Polymers and Polynuclear Closed Species. Dalton Trans. 2017, 46, $13660-13667$.

6. Burns, P. C. $\mathrm{U}^{6+}$ Minerals and Inorganic Compounds: Insights into an Expanded Structural Hierarchy of Crystal Structures. Can Mineral. 2005, 43, 1839-1894.

7. Mentzen, B. F.; Puaux, J. P.; Sautereau, H. The Crystal Structure of Diammonium Uranyl Tetraformate: $\left(\mathrm{NH}_{4}\right)_{2} \mathrm{UO}_{2}(\mathrm{HCOO})_{4}$. Acta Crystallogr., Sect. B 1978, 34, 1846-1849.

8. Thuéry, P. Uranyl Ion Complexes of Cucurbit[7]uril with Zero-, One-, and TwoDimensionality. CrystEngComm 2009, 11, 1150-1156.

9. Thuéry, P.; Atoini, Y.; Harrowfield, J. Chiral Discrete and Polymeric Uranyl Ion Complexes with $(1 R, 3 S)-(+)$-Camphorate Ligands: Counterion-Dependent Formation of a Hexanuclear Cage. Inorg. Chem. 2019, 58, 870-880.

10. Fankuchen, I. Crystal Structure of Sodium Uranyl Acetate. Z. Kristallogr. 1935, 91, 473-479.

11. Zachariasen, W. H.; Plettinger, H. A. Crystal Chemical Studies of the 5f-Series of Elements. XXV. The Crystal Structure of Sodium Uranyl Acetate. Acta Cryst. 1959, 12, 526-530.

12. Klepov, V. V.; Serezhkina, L. B.; Serezhkin, V. N.; Alekseev, E. V. Synthesis and Crystal Structure Analysis of Uranyl Triple Acetates. J. Solid State Chem. 2016, 244, 100-107.

13. Thuéry, P.; Atoini, Y.; Harrowfield, J. Uranyl-Organic Coordination Polymers with trans1,2-, trans-1,4-, and cis-1,4-Cyclohexanedicarboxylates: Effects of Bulky $\mathrm{PPh}_{4}{ }^{+}$and $\mathrm{PPh}_{3} \mathrm{Me}^{+}$ Counterions. Cryst. Growth Des. 2018, 18, 2609-2619. 
14. Thuéry, P.; Atoini, Y.; Harrowfield, J. Counterion-Controlled Formation of an Octanuclear Uranyl Cage with cis-1,2-Cyclohexanedicarboxylate Ligands. Inorg. Chem. 2018, 57, 62836288.

15. Thuéry, P.; Atoini, Y.; Harrowfield, J. Closed Uranyl-Dicarboxylate Oligomers: A Tetranuclear Metallatricycle with Uranyl Bridgeheads and 1,3-Adamantanediacetate Linkers. Inorg. Chem. 2018, 57, 7932-7939.

16. Thuéry, P.; Atoini, Y.; Harrowfield, J. Tubelike Uranyl-Phenylenediacetate Assemblies from Screening of Ligand Isomers and Structure-Directing Counterions. Inorg. Chem. 2019, 58, $6550-6564$.

17. Thuéry, P.; Harrowfield, J. $[\mathrm{Ni}(\text { cyclam })]^{2+}$ and $\left[\mathrm{Ni}\left(R, S-\mathrm{Me}_{6} \text { cyclam }\right)\right]^{2+}$ as Linkers or Counterions In Uranyl-Organic Species with cis- and trans-1,2-Cyclohexanedicarboxylate Ligands. Cryst. Growth Des. 2018, 18, 5512-5520.

18. Thuéry, P.; Atoini, Y.; Harrowfield, J. Structure-Directing Effects of Counterions in Uranyl Ion Complexes with Long-Chain Aliphatic $\alpha, \omega$-Dicarboxylates: 1D to Polycatenated 3D Species. Inorg. Chem. 2019, 58, 567-580.

19. Hooft, R. W. W. COLLECT, Nonius BV: Delft, The Netherlands, 1998.

20. Otwinowski, Z.; Minor, W. Processing of X-Ray Diffraction Data Collected in Oscillation Mode. Methods Enzymol. 1997, 276, 307-326.

21. Sheldrick, G. M. SHELXT - Integrated Space-Group and Crystal-Structure Determination. Acta Crystallogr., Sect. A 2015, 71, 3-8.

22. Sheldrick, G. M. Crystal Structure Refinement with SHELXL. Acta Crystallogr., Sect. C 2015, $71,3-8$.

23. Hübschle, C. B.; Sheldrick, G. M.; Dittrich, B. ShelXle: a Qt Graphical User Interface for SHELXL. J. Appl. Crystallogr. 2011, 44, 1281-1284. 
24. Farrugia, L. J. WinGX and ORTEP for Windows: an Update. J. Appl. Crystallogr. 2012, 45, $849-854$.

25. Momma, K.; Izumi, F. VESTA 3 for Three-Dimensional Visualization of Crystal, Volumetric and Morphology Data. J. Appl. Crystallogr. 2011, 44, 1272-1276.

26. Blatov V. A. Nanocluster Analysis of Intermetallic Structures with the Program Package TOPOS. Struct. Chem. 2012, 23, 955-963.

27. Thuéry, P.; Harrowfield, J. Anchoring Flexible Uranyl Dicarboxylate Chains through Stacking Interactions of Ancillary Ligands on Chiral U(VI) Centres. CrystEngComm 2016, 18, 39053918.

28. Spek, A. L. Structure Validation in Chemical Crystallography. Acta Crystallogr., Sect. D 2009, $65,148-155$.

29. Spackman, M. A.; Jayatilaka, D. Hirshfeld Surface Analysis. CrystEngComm 2009, 11, 1932.

30. Wolff, S. K.; Grimwood, D. J.; McKinnon, J. J.; Turner, M. J.; Jayatilaka, D.; Spackman, M.
A. CrystalExplorer; University of Western Australia: Crawley, Australia, 2012.

31. Taylor, R.; Kennard, O. Crystallographic Evidence for the Existence of $\mathrm{C}-\mathrm{H} \cdots \mathrm{O}, \mathrm{C}-\mathrm{H} \cdots \mathrm{N}$, and C-H‥Cl Hydrogen Bonds. J. Am. Chem. Soc. 1982, 104, 5063-5070.

32. Desiraju, G. R. The C-H‥O Hydrogen Bond: Structural Implications and Supramolecular Design. Acc. Chem. Res. 1996, 29, 441-449.

33. Zavalij, P. Y.; Burton, B. L.; Jones, W. E., Jr. New Structures in the Bipyridine-Copper(II) Nitrate-Methanol System: $\left[(\text { bpy })_{2} \mathrm{Cu}\left(\mathrm{NO}_{3}\right)\right] \mathrm{NO}_{3} \cdot \mathrm{CH}_{3} \mathrm{OH}$ and $\left[(\text { bpy })_{2} \mathrm{Cu}\left(\mathrm{NO}_{3}\right)\right] \mathrm{NO}_{3}$. Acta Crystallogr., Sect. C 2002, 58, m330-m333.

34. Beobide, G.; Castillo, O., García-Couceiro, U.; García-Terán, J. P.; Luque, A. Bis(2,2'bipyridine- $\left.\kappa^{2} N, N^{\prime}\right)($ nitrato- $\kappa O)$ copper(II) Hexafluorophosphate. Acta Crystallogr., Sect. E 2006, 62, m1353-m1355. 
35. Zhu, Y.; Wu, Y. L.; Huang, C. X.; Xie, J. M. Bis $\left(2,2^{\prime}-\right.$ bipyridine- $\left.\kappa^{2} N, N^{\prime}\right)($ nitrato- $\kappa O) \operatorname{copper(II)}$ Perchlorate. Acta Crystallogr., Sect. E 2011, 67, m306.

36. Thuéry, P.; Harrowfield, J. Modulation of the Structure and Properties of Uranyl Ion Coordination Polymers Derived from 1,3,5-Benzenetriacetate by Incorporation of $\mathrm{Ag}(\mathrm{I})$ or $\mathrm{Pb}(\mathrm{II})$. Inorg. Chem. 2016, 55, 6799-6816.

37. Thuéry, P.; Harrowfield, J. Variations on the Honeycomb Topology: From Triangular- and Square-Grooved Networks to Tubular Assemblies in Uranyl Tricarballylate Complexes. Cryst. Growth Des. 2017, 17, 963-966.

38. Thuéry, $\mathrm{P}$.; Harrowfield, J. $\mathrm{Ag}^{\mathrm{I}}$ and $\mathrm{Pb}^{\mathrm{II}}$ as Additional Assembling Cations in Uranyl Coordination Polymers and Frameworks. Cryst. Growth Des. 2017, 17, 2116-2130.

39. Thuéry, P.; Harrowfield, J. Structural Consequences of 1,4-Cyclohexanedicarboxylate Cis/Trans Isomerism in Uranyl Ion Complexes: From Molecular Species to 2D and 3D Entangled Nets. Inorg. Chem. 2017, 56, 13464-13481.

40. Thuéry, P.; Harrowfield, J. Tetrahydrofurantetracarboxylic Acid: An Isomerizable Framework-Forming Ligand in Homo- and Heterometallic Complexes with $\mathrm{UO}_{2}{ }^{2+}, \mathrm{Ag}^{+}$and $\mathrm{Pb}^{2+}$. Cryst. Growth Des. 2016, 16, 7083-7093.

41. Bell, N. L.; Arnold, P. L.; Love, J. B. Controlling Uranyl Oxo Group Interactions to Group 14 Elements Using Polypyrrolic Schiff-Base Macrocyclic Ligands. Dalton Trans. 2016, 45, $15902-15909$.

42. Moseley, P. T. Aspects of the Structural Chemistry of Lanthanide and Actinide Compounds. In Inorganic Chemistry, Series Two, Vol.7: Lanthanides and Actinides; Bagnall, K. W., Ed.; Butterworths: London, and University Park Press: Baltimore, 1975; Chapter 3, pp. 65-110.

43. Shimoni-Livny, L.; Glusker, J. P.; Bock, C. W. Lone Pair Functionality in Divalent Lead Compounds. Inorg. Chem. 1998, 37, 1853-1867. 
44. Thuéry, P.; Atoini, Y.; Harrowfield, J. The Sulfonate Group as a Ligand: a Fine Balance between Hydrogen Bonding and Metal Ion Coordination in Uranyl Ion Complexes. Dalton Trans. 2019, 48, 8756-8772.

45. Thuéry, P.; Harrowfield, J. Uranyl Ion Complexes with Long-Chain Aliphatic $\alpha, \omega-$ Dicarboxylates and 3d-Block Metal Counterions. Inorg. Chem. 2016, 55, 2133-2145.

46. Thuéry, P.; Harrowfield, J. Coordination Polymers and Cage-Containing Frameworks in Uranyl Ion Complexes with rac- and (1R,2R)-trans-1,2-Cyclohexanedicarboxylates: Consequences of Chirality. Inorg. Chem. 2017, 56, 1455-1469.

47. Thuéry, P.; Harrowfield, J. Tetrahedral and Cuboidal Clusters in Complexes of Uranyl and Alkali or Alkaline-Earth Metal Ions with rac- and (1R,2R)-trans-1,2Cyclohexanedicarboxylate. Cryst. Growth Des. 2017, 17, 2881-2892.

48. Caulder, D. L.; Raymond, K. N. Supermolecules by Design. Acc.Chem. Res. 1999, 32, 975-982.

49. Burrows, H. D.; Formosinho, S. J.; Miguel, M. da G.; Pinto Coelho, F. Quenching of the Luminescent State of the Uranyl Ion $\left(\mathrm{UO}_{2}{ }^{2+}\right)$ by Metal Ions. Evidence for an Electron Transfer Mechanism. J. Chem. Soc., Faraday Trans. 1 1976, 72, 163-171.

50. Kerr, A. T.; Cahill, C. L. Postsynthetic Rearrangement/Metalation as a Route to Bimetallic Uranyl Coordination Polymers: Syntheses, Structures, and Luminescence. Cryst. Growth Des. 2014, 14, 1914-1921.

51. Kerr, A. T.; Cahill, C. L. CuPYDC Metalloligands and Postsynthetic Rearrangement/Metalation as Routes to Bimetallic Uranyl Containing Hybrid Materials: Syntheses, Structures, and Fluorescence. Cryst. Growth Des. 2014, 14, 4094-4103.

52. Ridenour, J. A.; Pyrch, M. M.; Manning, Z. J.; Bertke, J. A.; Cahill, C. L. Two Novel Bimetallic Transition Metal-Uranyl One-Dimensional Coordination Polymers with 
Manganese(II) and Cobalt(II) Incorporating Bridging Diglycolate (2,2'-oxydiacetate) Ligands. Acta Crystallogr., Sect. C 2017, 73, 588-592.

53. Kerr, A. T.; Ridenour, J. A.; Noring, A. A.; Cahill, C. L. Two Uranyl-Copper(II) Bimetallic Coordination Polymers Containing trans-3,3(pyridyl)acrylic acid: Structural Variance Through Synthetic Subtleties. Inorg. Chim. Acta 2019, 494, 204-210.

54. Gomez, G. E.; Ridenour, J. A.; Byrne, N. M.; Shevchenko, A. P.; Cahill, C. L. Novel Heterometallic Uranyl-Transition Metal Materials: Structure, Topology, and Solid State Photoluminescence Properties. Inorg. Chem. 2019, 58, 7243-7254.

55. Brachmann, A.; Geipel, G.; Bernhard, G.; Nitsche, H. Study of Uranyl(VI) Malonate Complexation by Time Resolved Laser-Induced Fluorescence Spectroscopy (TRLFS). Radiochim. Acta 2002, 90, 147-153. 
For Table of Contents Use Only

\section{1,2-, 1,3- and 1,4-Phenylenediacetate Complexes of Uranyl Ion with Additional Metal Cations and/or Ancillary $N$-Donor Ligands: Confronting Ligand Geometrical Proclivities}

Pierre Thuéry, Youssef Atoini and Jack Harrowfield

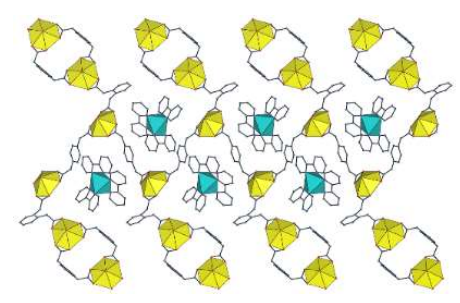

The 1,2-1,3- and 1,4-phenylenediacetate ligands have a strong propensity to give 1D uranyl ion complexes, a tendency which can only be partially overcome through the incorporation of additional metal cations, either bound to $N$-donors to form bulky, structure-directing counterions, or part of heterometallic polymers. 